\title{
X. Kunstraub und Judenverfolgung
}

\author{
1. „Schlagartig in getarnter Form“: \\ Beutezug der Botschaft mit Hindernissen
}

Der mit Haken und Ösen geführte Machtkampf gegen die Propaganda-Abteilung, der ihm die erbitterte Feindschaft Goebbels' eintrug, und seine auch bei den Militärs noch ungefestigte, im wesentlichen auf Ribbentrops Gunst bei Hitler basierende Stellung setzten Otto Abetz im Sommer 1940 unter erheblichen Erfolgszwang. Um sich als eigenständige Kraft in Paris zu etablieren, mußte er Arbeitsnachweise, tunlichst Ergebnisse präsentieren. Der Druck, sich gegen Rivalen vor Ort und in den Augen argwöhnischer Berliner Potentaten als verläßlicher Nationalsozialist zu behaupten, mag einiges von der skrupellosen Vehemenz, ja kriminellen Energie erklären, mit welcher er bestimmte Themen anpackte und für seine Zwecke instrumentalisierte. Für eine positive Gestaltung des deutsch-französischen Verhältnisses waren sie aus seinem Blickwinkel nachrangig. Doch fast zwangsläufig fielen moralische Schranken, drehte sich die Spirale persönlicher Verstrickung und Schuld. Grelles Licht hierauf wirft Abetz' Rolle beim euphemistisch als „Sicherstellung" deklarierten Raub staatlicher und privater, vor allem jüdischer Kunstschätze in Frankreich. Aller rhetorischen Beweglichkeit zum Trotz, die sein Handeln im nachhinein als gute Tat zugunsten eines unversehrten Kulturerbes bemänteln wollte, ist festzuhalten: Unter seiner Verantwortung wurden 1940 Hunderte von Kunstwerken auf kaltem Weg enteignet, ins Inventar der Botschaft übernommen oder ins Reich abtransportiert. Ein Chronist der Militärverwaltung kam nicht umhin, eine "dem Friedensschluß vorgreifende Beutenahme“ anzuprangern; Abetz habe „den Gerüchten über den deutschen Kunstraub [...] als erster einen tatsächlichen Untergrund geliefert" ${ }^{\text {" }}$. Die französische Anklage vor dem Internationalen Militärgerichtshof in Nürnberg sprach von einem „klaren Plünderungsakt" 2 .

Die erste Initiative ging offenbar von Ribbentrop aus. Auf seinen Vortrag verfügte Hitler nach dem siegreichen Westfeldzug, Kunstschätze aus französischem Staatsbesitz, aber auch private, vornehmlich jüdische Sammlungen seien in $\mathrm{Ge}-$ wahrsam der Besatzungsmacht zu überführen, angeblich um eine „Verschleppung

1 „Bericht über die Wegnahme französischer Kunstschätze durch die deutsche Botschaft und den Einsatzstab Rosenberg in Frankreich“, zusammengestell im Januar 1945 von Walter Bargatzky [„Bargatzky-Bericht“], S. 299. Jurist Bargatzky, Jg. 1910, gehörte zur Gruppe Justiz im Verwaltungsstab des Militärbefehlshabers Frankreich.

2 Exposé zum Thema Kunstraub von Charles Gerthoffer, Hilfsankläger für die Französische Republik, 6. 2. 1946; IMT, VII, S. 64. Vgl. das Plädoyer des Abetz-Anklägers, 21. 7. 1949: „sur ce point sa culpabilité est entière“. AN, 334 AP 49, „Réquisitoire de M. le Commissaire du Gouvernement Flicoteaux“, pag. 18. Der Schuldspruch gegen Abetz stützte sich unter anderem auf den Artikel 221 des Militärstrafgesetzbuches („complicité de pillage ${ }^{\alpha}$ ) und eine einschlägige Gesetzesverordnung vom 28. 8. 1944. 
bezw. Verbergung“ zu verhindern und „als Pfand für die Friedensverhandlun-

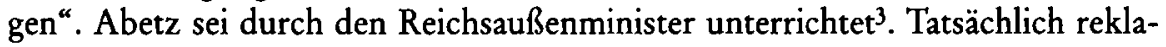
mierte der Gesandte am 1. Juli 1940 den offiziellen Auftrag, die Berliner Order umzusetzen; im selben Atemzug bat er die Militärverwaltung um Unterstützung. Die wertvollsten Kulturgüter sollten in die Deutsche Botschaft gebracht werden ${ }^{4}$. Zur Auswahl und Katalogisierung schickte das Auswärtige Amt umgehend Kunstsachverständige nach Paris 5 .

$\mathrm{Daß}$ man sich in der Rue de Lille schon seit Tagen mit der Materie beschäftigte, dokumentieren Akten der Geheimen Feldpolizei (GFP), einem Exekutivorgan der Militärverwaltung. Sie berichten von einer Besprechung im Botschaftsgebäude am 24. Juni, in welcher die „Frage der Sicherung der Kunstschätze von Paris" erörtert wurde. Schleier bekundete reges Interesse an einer Inventur, was in der Hauptstadt zurückgelassen beziehungsweise vor dem Einmarsch deutscher Truppen fortgeschafft worden war. Abetz verteilte Listen der bislang lokalisierten Bestände, die es zu vervollständigen galt ${ }^{6}$. Ausgestattet mit einem „Sonderauftrag, die Kunstschätze des Staates Frankreich sicherzustellen", inspizierten sodann GFP-Kommandos in der letzten Juni-Woche Depots, die die Direktion der Musées Nationaux zu Kriegsbeginn überwiegend in Loire-Schlössern eingerichtet hatte. Das zur Bewachung aufgebotene Museumspersonal mußte schriftlich erklären, daß die eingelagerten Kunstwerke vollzählig und unbeschädigt seien. Vorhandene Transportlisten wurden eingesammelt und dem speziell mit dieser Angelegenheit befaßten Karl Epting ausgehändigt. Ein im Département Sarthe entdecktes Depot des Pariser Kunsthändlers Wildenstein „sicherten" die Polizisten „in einer geeigneten Weise" ${ }^{\text {" }}$.

Am 2. Juli trafen Abetz und Epting organisatorische Vorbereitungen für eine große Razzia in jüdischen Pariser Kunst- und Antiquitätengeschäften. Feldpolizeidirektor Dr. Oehme wurde in die Rue de Lille einbestellt und instruiert, die Operation müsse "schlagartig in getarnter Form“, am besten spätabends oder im Morgengrauen laufen. Für Außenstehende dürfe nicht erkennbar sein, wer die

3 Keitel (OKW) an den Militärbefehlshaber von Paris, General v. Bockelberg, 30. 6. 1940; IMT, RF-1301, abgedruckt bei Brenner, Kunstpolitik, S. 218.

4 Abetz an Militärbefehlshaber Paris, 1. 7. 1940; IMT, RF-1334, abgedruckt ebenda, S. 219.

5 Vgl. Luther (Abt. Deutschland) an den Bayerischen Staatsminister für Unterricht und Kultus, Gauleiter Adolf Wagner, 16. 12. 1940; PA/AA, R 27648. Dringlichste Aufgabe der Experten laut Luther: den jüdischen Kunstbesitz in Paris „in bezug auf seine Eignung und zur Überführung nach Deutschland zu prüfen".

6 Bericht der GFP-Gruppe 550 (gez. Feldpolizeidirektor Greiner), 24. 6. 1940, und Vermerk im GFP-Tagebuch Nr. 38/40 vom selben Tag; AN, F 7/15151, Dossier 3. „Dienstliche Äußerung des Feldpolizeidirektors Dr. Oehme, Gruppe GFP 540“ vom 8. Juli; CDJC, LXXI-22.

7 Abschlußbericht der GFP vom 7. Juli, Einzelberichte der beteiligten Kommandos vom 30. Juni bis 3. Juli; AN, F 7/15151. Bericht der Münchener Gobelin-Manufaktur, die einen Spezialisten mitgeschickt hatte, an das Auswärtige Amt, 10. Juli; PA/AA, R 27655. Epting interpretierte seine Tätigkeit später dergestalt, daß er die "Versiegelung "staatlicher und privater Kunstschätze überwacht habe, um sie vor Unbill zu schützen. Verhörprotokoll der Direction des Renseignements Généraux vom 10.6. 1947; AN, 3 W 358, Dossier Epting. 
Kunstgegenstände beschlagnahme und wohin sie verbracht würden. Für ihre Unterbringung trage die Botschaft Sorge. Zerbrechliche Objekte sollten einstweilen nur registriert, die Räume anschließend mit einem Siegel der polnischen Gesandtschaft (!) verschlossen werden. Epting überreichte eine Liste mit rund 80 Firmennamen -15 waren mit Bleistift angekreuzt ${ }^{8}$.

Oehme und seinen Kameraden war offenkundig unwohl bei diesem Auftrag. Gegenüber SD-Vertretern wandten sie ein, das Vorhaben sei „sowohl im Hinblick auf das Ansehen der Wehrmacht als auch wegen technischer Schwierigkeiten" suspekt. Der Chef des Kommandostabes der Militärverwaltung, Oberstleutnant Speidel, versuchte ebenfalls zu bremsen. Abetz indessen setzte sich nach einigem Hin und Her durch, darauf pochend, daß ein ,Führer'-Befehl vorliege, der schnellstens befolgt werden müsse, und unter Hinweis auf Keitels Order vom 30. Juni. Unmittelbar vor Beginn der Razzia suggerierte er dem zaudernden Oehme, Speidel habe nun endgültig grünes Licht gegeben?.

So schwärmten denn am Morgen des 6. Juli Kommandos der GFP-Gruppen 171 und 540 aus. Sie durchkämmten die renommierten Kunsthandlungen Arnold, Jacques und Andrej Seligmann, Bernheim jeune, Paul Rosenberg, Devalcourt, Lévy, Reitlinger, Mayer, Georges und Tannhauser, ferner die Galerien Montaigne, Gaston \& Lucien Manuel, Henry Manuel sowie Privatwohnungen von Inhabern, leitenden Angestellten und jüdischen Kunstmäzenen, unter ihnen mehrere Mitglieder der Familie Rothschild. Was immer die begleitenden Kunstexperten des Auswärtigen Amts für kostbar erachteten, wurde auf Lastwagen verladen, in ein Nebengebäude der Botschaft transportiert und dort gegen Quittung in Empfang genommen - alles in allem mehrere hundert Möbel, Leuchter, Gemälde, Plastiken, Vasen, Uhren, Kupferstiche, Gobelins und so fort. Ein detailliertes Verzeichnis mit Angaben über Künstler und Motive, Alter, Material und Marktwert füllt 152 Seiten. Aus welcher Kunsthandlung die Objekte jeweils stammten, konnte der Chronist wegen schludrig geführter Listen der GFP nicht mehr in allen Fällen zuverlässig sagen ${ }^{10}$. Besonders reiche Beute machten die Fahnder bei den Seligmanns, während sie in etwa der Hälfte der Geschäfte leer ausgingen - die Inhaber hatten ihre Wertsachen vorsorglich evakuiert ${ }^{11}$. Zwischenfälle blieben aus, doch

8 Aktennotiz Oehme, 2. 7. 1940; CDJC, LXXI-8. "Dienstliche Äußerung“ vom 8. Juli mit Anschreiben des Feldpolizeidirektors Sowa an den Militärbefehlshaber von Paris; CDJC, LXXI-22 und 23. Abetz hat die Konferenz am 2. Juli 1940 vor Gericht bestätigt. AbetzProzeß, 15. 7. 1949, pag. 7; AN, 334 AP 49.

9 „Dienstliche Äußerung“ Oehmes, ebenda.

10 Sonderband ,Jüdischer Kunstbesitz in Frankreich, seine Sicherstellung (Februar 1941Juni 1943), geheim“, Anlage 1: „Verzeichnis der im Juli 1940 durch die Geheime Feldpolizei in Paris gesicherten und in die Deutsche Botschaft überbrachten Gegenstände aus jüdischen Kunsthandlungen. Wissenschaftlich bearbeitet im Juli und August 1940. Dr. Erich Meyer, Berlin C 2, Schloßmuseum"; PA/AA, Botschaft Paris 2490. Meyer war Kustos an den Staatlichen Museen in Berlin.

11 Die Razzia ist im Aktenkonvolut AN, F 7/15151, Dossier 4 durch Protokolle der einzelnen Suchtrupps, Listen der beschlagnahmten Gegenstände und eine Aufzeichnung Oehmes vom 7. Juli lückenlos dokumentiert. Siehe ferner die Darstellung bei Kurz, Kunstraub in Europa, S. 135 f., und bei Nicholas, Der Raub der Europa, S. 170. Beide Autoren be- 
mußte die Operation am 8. Juli gegen Mittag auf Intervention Speidels abgebrochen werden. Er war nach Aktenlage über den genauen Einsatzzweck der GFP wohl bewußt im unklaren gelassen worden und anscheinend davon ausgegangen, daß Botschaftsangehörige die in Paris verbliebenen Kunstschätze lediglich an Ort und Stelle sichten wollten ${ }^{12}$. Eines Besseren belehrt, pfiff er die Polizisten zurück. Sie beriefen sich auf den Keitel-Befehl vom 30. Juni. Feldpolizeidirektor Sowa verwahrte sich „ganz entschieden“" gegen Vorwürfe, pflichtwidrig und außerhalb des Dienstweges gehandelt zu haben ${ }^{13}$.

Seiner Hilfstruppen ledig, kümmerte sich Abetz sofort um Ersatz. Schon am nächsten Tag wurde Legationssekretär Frhr. v. Künsberg, erprobt im Aufspüren politischer Archive, von Ribbentrop angewiesen, sich dem Gesandten „für Sonderauftrag betreffend Kunstgegenstände zur Verfügung [zu] stellen " ${ }^{14}$. Künsberg meldete sich am 10. Juli bei Abetz und erfuhr, „daß die Aktion in der Stadt Paris selbst als abgeschlossen zu betrachten sei und nur noch die Sicherstellung von verschleppten Kunstgegenständen auf dem Lande durchgeführt werden müsse"15. Die Dokumente sprechen eine deutliche Sprache; wenig glaubwürdig muten dagegen Abetz' Beteuerungen vor Gericht an, Künsberg sei unabhängig von der Botschaft und nur auf direkte Weisung aus Berlin tätig geworden ${ }^{16}$. Genauso dünn ist seine Behauptung, die Razzia Anfang Juli 1940 habe einzig dem Zweck gedient, in früheren Jahren illegal von Deutschland nach Frankreich exportiertes Kulturgut zu konfiszieren. Der Vorsitzende Richter Pihier verwies diese Version gewiß zu Recht ins Reich der Fabel ${ }^{17}$. Dem Geschehen im nachhinein einen legalen Anstrich zu geben, ist dem Angeklagten nicht gelungen. Und auch seine bemüht positive, den Interessen der Eigentümer Schutz verheißende Interpretation des Begriffs „Sicherstellung“ schürte allenfalls den Unmut des Tribunals, statt ihn, wie erhofft, zu entlasten ${ }^{18}$.

Nach dem ergiebigen Beutezug durch jüdische Geschäfte rückten nun erneut staatliche Depots ins Visier, namentlich das Loire-Schloß Chambord, das Teile der Louvre-Sammlungen beherbergte. Dorthin schwärmten Künsbergs Leute am 22. Juli aus, um „Sicherstellungen vorzunehmen“; er selbst wollte den Abtransport leiten ${ }^{19}$. Am 27. meldete das Kommando Vollzug: „Umfang 410 Kisten, 139 sonstige Gemälde, 67 Ballen Tapisserien, 216 Stück Möbel.“ Die „Verbringung nach Berlin“, für die die vorhandenen Lastkraftwagen sich als ungeeignet erwiesen, so daß eine Hinzuziehung von Fachunternehmen als notwendig erschien,

richten von einer Beteiligung des Sonderkommandos v. Künsberg schon zu diesem Zeitpunkt, wofür sich weder in den GFP- noch in den Künsberg-Akten Hinweise finden.

$12 \mathrm{Vgl}$. „Dienstliche Äußerung “ Oehmes, wie Anm. 8.

13 Sowa an Bockelberg, 8. 7. 1940; AN, F 7/15151.

14 v. Halem (Berlin) an Botschaft Paris, 9. 7. 1940. Zuvor Luther an v. Halem, 8. Juli (Stichwort: „wegen der sofortigen Beschlagnahme von Kunstgegenständen“); PA/AA, R 27578.

15 Aufzeichnung Künsberg vom 1.11. 1940, „Betrifft: Französische Kunstgegenstände“; PA/AA, R 27579.

16 Abetz-Prozeß, 15. 7. 1949, pag. 33, 36; AN, 334 AP 49.

17 Ebenda, pag. $17 \mathrm{ff}$.

18 Ebenda, pag. $21 \mathrm{f}$.

19 Aufzeichnung Künsberg, 21. 7. 1940; PA/AA, R 27578. 
müsse nur noch von der Militärverwaltung genehmigt werden ${ }^{20}$. Das „Majestic“ aber lehnte rundweg ab: Ein Transport nach Deutschland sei nicht geplant. Überdies befremde den Oberbefehlshaber des Heeres, daß der ,Führer' dem Auswärtigen Amt einen derartigen Auftrag erteilt haben sollte ${ }^{21}$.

Bei den Statthaltern des Waffenstillstandsregimes hatte sich entschiedener Widerstand gegen Abetz' Aktivitäten formiert. Treibende Kraft war der angesehene Kunsthistoriker Prof. Dr. Franz Graf Wolff Metternich, Konservator der Rheinprovinz, jetzt OKH-Beauftragter für Kunstschutz in den besetzten Gebieten. Seine Richtlinien geboten den Schutz von Denkmälern und beweglichen Kunstschätzen vor Zerstörung und Verschleppung, und er gedachte sie buchstabengetreu anzuwenden. Die Ehre von Wehrmacht und Staat, aber auch ein geordnetes Besatzungsregime standen auf dem Spiel. Vor allem der Einzug von Privateigentum - wozu Metternich und seine Mitarbeiter jüdischen Kunstbesitz ausdrücklich zählten - wurde als klarer Verstoß gegen das Völkerrecht und die einschlägigen Artikel der Haager Landkriegsordnung von 1907 verurteilt 22 . Diese Haltung schlug sich in einer Verordnung des Militärbefehlshabers vom 15. Juli 1940 nieder, die jedes Entfernen beweglicher Kunstwerke vom derzeitigen Aufbewahrungsort und Rechtsgeschäfte mit ihnen ohne schriftliches Placet der Militärverwaltung untersagte ${ }^{23}$. Damit sollte den für illegal erachteten Praktiken von Abetz und Künsberg, die sich in Metternichs Augen wie „eine Art moderner Freibeuter" aufführten, ein Riegel vorgeschoben werden ${ }^{24}$.

Am 17. Juli eröffnete Abetz Künsberg, es bestünden „größte Schwierigkeiten von seiten der Militärbehörde, über [die] Deutsche Botschaft Paris Kunstgegenstände zu beschlagnahmen " 25 . Kampferprobt und gewohnt, Widerstände zu brechen, ließen der Gesandte und sein Chef Ribbentrop indes nicht locker. Staatssekretär v. Weizsäcker sollte bei Keitel intervenieren und dafür sorgen, „daß ggf. vorhandene Mißverständnisse bei den Militärbehörden in Paris beseitigt werden“26. Keitel schien kompromißbereit; er wollte die Pariser Militärs anweisen, Abetz' ,jetzigen Auftrag“ zu unterstützen ${ }^{27}$. Seinen Worten folgten aber offenbar keine Taten. Sollte der versuchte Abtransport von Kunstwerken aus Chambord Ende Juli eine Nagelprobe gewesen sein, ob die Militärverwaltung die Botschaft künftig gewähren ließe, so ist sie jedenfalls mißlungen. Welch zweifelhafte $\mathrm{Ab}$ sichten Abetz mit dem Begriff „in Gewahrsam nehmen“ im übrigen verband, ent-

20 Nitsch (Künsberg-Mitarbeiter) an Auswärtiges Amt, 27. Juli; PA/AA, R 27579.

21 Nitsch an Auswärtiges Amt, 30. Juli, mit abschlägigem Bescheid vom 29. Juli, ebenda. Vgl. Kurz, Kunstraub, S. 138.

22 Vgl. Franz Graf Wolff Metternich, „Über meine Tätigkeit als Beauftragter des Oberkommandos des Heeres für den Schutz der Werke der bildenden Kunst von 1940-42. Grundsätze und Arbeitsmethoden“, undatiert, 21 S.; CDJC, XIII-46 (= IMT, RF-1318). „Bargatzky-Bericht“, bes. S. $324 \mathrm{ff}$. Zur Geschichte des militärischen Kunstschutzes, seiner Organisation und seinen Aufgaben im besetzten Frankreich Günther-Hornig, Kunstschutz, S. 1-13, 33-48.

23 Verordnungsblatt für die besetzten französischen Gebiete, Nr. 3 vom 15. 7. 1940.

24 Metternich, „Über meine Tätigkeit“, pag. $11 \mathrm{ff}$.

25 Aufzeichnung Künsberg vom 1. 11. 1940; PA/AA, R 27579.

26 Künsberg an Weizsäcker, 21. 7. 1940; PA/AA, R 27578.

27 Aufzeichnung Weizsäcker, 22. Juli; PA/AA, R 27579. 
hüllen die Akten an diesem Punkt fast beiläufig: Als zwölf Lastkraftwagen des Sonderkommandos Künsberg, mit Archiven der ehemaligen tschechischen und polnischen Gesandtschaft Paris und anderer Kriegsbeute beladen, am 1. August nach Berlin aufbrachen, hatten sie auf Abetz' Wunsch auch wertvolle Teppiche, bei der Razzia in jüdischen Geschäften und Wohnungen, sichergestellt', im Gepäck. Aus dem Salzburger Land, wo er sich auf seine wichtige Audienz bei Hitler vorbereitete, kabelte der designierte Botschafter am 30. Juli an Schleier, die „15 größten und schönsten Teppiche des Nebengebäudes" seien zu verladen, auf daß sie in der Reichshauptstadt geschätzt würden. Unterdessen wies Künsberg seine Leute auf die Notwendigkeit hin, einen Fahrbefehl zu erwirken, „worin die Gegenstände als Eigentum des AA deklariert sind“ ${ }^{\text {28 }}$.

Im Bemühen, die Militärverwaltung auszuhebeln, setzte Ribbentrop nun auf eine Stärkung der Abetzschen Kompetenzen. Als sein Pariser Statthalter am 3. August 1940 von Hitler zum Botschafter ernannt wurde, sorgte der Reichsaußenminister dafür, daß im Aufgabenkatalog die „Sicherstellung und Erfassung des öffentlichen Kunstbesitzes, ferner des privaten und vor allem jüdischen Kunstbesitzes auf Grund besonderer hierzu erteilter Weisungen" auftauchte" ${ }^{29}$. Gleichzeitig wurde Künsberg der Rue de Lille „zur Durchführung von Sonderaufgaben [...] unmittelbar zugeteil “"30. Solchermaßen gewappnet, führte Abetz in den nächsten Wochen einen wüsten Grabenkrieg gegen die Militärverwaltung. Die Kunstschutz-Verordnung vom 15. Juli geflissentlich ignorierend, fuhren Künsberg und Angehörige der Botschaft am 11. August nach Saumur, um dort die Originale der Friedensverträge von Versailles und Saint Germain aufzuspüren. Sie wurden „ordnungsgemäß an die Deutsche Botschaft Paris abgeliefert“. Der Folgeauftrag lautete, französische Staatssammlungen „zu überholen und nach bestimmten Richtlinien Kunstschätze im Auftrag des Führers auszusuchen und zu sichern" ${ }^{31}$. Etwa 1500 Gemälde sollten nach Informationen der Militärverwaltung aus Chambord und anderen Orten abtransportiert werden ${ }^{32}$. Graf Wolff Metternich bekam jedoch rechtzeitig Wind davon und schlug Alarm. Der Oberbefehlshaber des Heeres, v. Brauchitsch, ließ daraufhin die Depots bewachen; noch am 11. August erneuerte er das "Verbringungsverbot ${ }^{\text {" }}$ vom 15 . Juli und unterstrich, $\mathrm{da} ß$ ihm bis dato kein verbindlicher, Führer'-Befehl vorliege.

28 Abetz (Fuschl) an Schleier (Paris), 30. Juli; Künsberg an Nitsch, 31. Juli; Aufzeichnung Nitsch vom 2. August; ebenda. In den Verzeichnissen der Pariser Botschaft ist die Sendung säuberlich vermerkt; PA/AA, Botschaft Paris 2490, Anlage 1. Für wen sie bestimmt war, verschweigen die Akten, doch war Ribbentrops Faible für Teppiche kein Geheimnis. „Die schönsten Teppiche, die er je gesehen, habe Ribbentrop“, schwärmte Hitler im März 1942 in der "Wolfsschanze“. Zit. von Picker, Hitlers Tischgespräche, Nr. 37, S. 128.

29 Der Reichsaußenminister an den Chef des Oberkommandos der Wehrmacht, 3. 8. 1940; ADAP, D X, Nr. 282.

30 Aktenotiz vom 3. August; PA/AA, R 27579.

31 GFP-Gruppe 627, Sonderkommando Gerum, „Tätigkeitsbericht vom 30. 7. bis 12. 8. 40“ (13. August); PA/AA, R 27528.

32 Vgl. Bericht Streccius an v. Brauchitsch, 13. 9. 1940, zit. in „Bargatzky-Bericht", S. 295; dort auch zum Folgenden. Außerdem Kurz, Kunstraub, S. 138ff.; Metternich, „Über meine Tätigkeit ${ }^{\alpha}$, pag. $15 \mathrm{f}$.; Bargatzky, Hotel Majestic, S. $66 \mathrm{f}$. 
In der Rue de Lille sann man vergrätzt nach anderen Mitteln. Bei einer Besprechung am 12. August regten Mitarbeiter des Botschafters an, Kunstwerke aus Schloß Chambord unter dem Vorwand, sie seien dort mangelhaft verstaut, in den Louvre zu bringen, um sodann in Ruhe auszuwählen und den Weitertransport nach Deutschland zu organisieren. Metternich, von Künsberg tags darauf um Unterstützung angegangen, war entschlossen, auch diesen „schamlosen“ Plan zu torpedieren, wiewohl er um seinen Posten bangte. Offene Ablehnung, so Zeitzeuge Bargatzky, „mochte zwar dem eigenen Ehren- und Rechtsstandpunkt Genüge tun, sie trug aber die Gefahr in sich, daß sie als Obstruktion nach oben gemeldet und daß durch einfachen Personalwechsel den verhinderten Absichten freie Bahn geschaffen wurde. Damit wären auch die letzten Hemmnisse für eine Ausbeutung der französischen Kunstschätze gefallen." Deshalb sagte Metternich zu, von den Franzosen Verzeichnisse der evakuierten Kunstwerke zu erbitten - nicht zuletzt, um selber einen Überblick zu gewinnen 33 .

Mit Genehmigung des Chefs der Militärverwaltung, Streccius, besichtigten Angehörige des Kommandos Künsberg und der Botschaft sowie drei Experten der Staatlichen Museen Berlin am 15. August die Schlösser Chambord, Chéverny und Brissac. Für Abetz war die Inspektion ein neuerlicher Rückschlag insofern, als die Sachverständigen an Unterbringung und Betreuung der Sammlungen nichts auszusetzen hatten - womit die am 12. August ausgeheckte List entfiel ${ }^{34}$. Doch Abetz dachte nicht daran, klein beizugeben. In einem Antrag an das OKH begehrte er, künftig frei von Auflagen der Militärverwaltung operieren zu können. Nach Streccius äußerte er in diesem Zusammenhang den Willen, die angeforderten Verzeichnisse persönlich zu prüfen und etwa zwei Dutzend "Werke von hervorragendem Wert auszuwählen, und zwar unabhängig davon, ob dieselben früher von den Franzosen geraubt seien oder nicht" 35 . Moderater formuliert ist ein Schreiben an Brauchitsch, in dem Abetz Vorschläge für eine in seinen Augen konstruktive Zusammenarbeit entwickelt. Conditio sine qua non: Künsberg hatte die gesamte Aktion nach seinen Weisungen zu leiten, flankiert von Geheimer Feldpolizei und Metternich, der sich den Sachverständigen der Botschaft anschließen mochte. Aufgrund der in Arbeit befindlichen Listen würden Hitler und Ribbentrop über den Verbleib der aufgefundenen Kunstschätze entscheiden. Des weiteren regte Abetz an, die einzelnen Objekte von deutschen und französischen Experten schätzen zu lassen. Bezeichnend für sein Verständnis von Eigentum ist der Zusatz: „Bei Kunstwerken, die nicht Gegenstand des Friedensvertrags werden sollen, sondern als Vorschußleistungen auf Reparation etwa sofort in Reichsbesitz zu überführen sind, empfehle ich Entrichtung des vollen Kaufwerts durch die das Kunstwerk empfangende Reichsstelle an eine zu schaffende Treuhandkasse. Über die spätere Verwendung der Beträge [...] reiche ich Vorschläge nach. ${ }^{\text {36 }}$

33 „Bargatzky-Bericht", S. 296.

34 Ebenda. Siehe ferner Bericht der GFP-Gruppe 627 (Gerum) vom 30. 8. 1940; PA/AA, R 27528. Gerum zufolge wurde nicht Chéverny, sondern Amboise besucht.

35 Streccius an Brauchitsch, 13. 9. 1940; „Bargatzky-Bericht", S. 296.

36 Abetz, Aufzeichnung für Brauchitsch („Betr.: Kunstschätze“), 16. 8. 1940; PA/AA, R 27355. Hinsichtlich der angekündigten Vorschläge hielt Abetz Wort: In einer Denk- 
Brauchitsch antwortete ungerührt, es bleibe bei seinem Verdikt vom 11. August $^{37}$. In Anbetracht dessen übertrieb Abetz, wenn er in einem Telegramm an Ribbentrop vom 22. August behauptete, Transporte von Kunstwerken „nach einer vorläufigen Sammelstelle in Paris" seien im Gange ${ }^{38}$. Damit konnte allenfalls jüdischer Besitz gemeint sein, nicht staatlicher, um den weiter erbittert gerungen wurde. Die Kreise des Botschafters einzuengen, versuchte just zum damaligen Zeitpunkt auch Goebbels, auf dessen Zureden Hitler nun plötzlich bestimmte, in Sachen Erfassung und Sicherstellung französischer Kunstschätze habe Abetz „nur Anweisungen des Reichspropagandaministers zu befolgen" 39 - eine Kehrtwende gegenüber den erst kürzlich auf Betreiben Ribbentrops zugebilligten Vollmachten. „Das hat nun der eitle Geck davon“, triumphierte Goebbels. „Er provoziert mich und bekommt dafür vom Führer die verdienten Ohrfeigen. Ich gönne sie ihm von Herzen. " 40 Hitlers Chefpropagandist koordinierte Forderungen diverser NS-Behörden, in früheren Kriegen nach Frankreich verbrachte Kunstwerke heim ins Reich zu holen. Interministerielle Arbeitszirkel in Berlin trugen die deutschen Desiderata zusammen. Goebbels ermunterte sie, hierbei nicht zimperlich zu sein: Aufzulisten sei alles, "wofür sich ein Anspruch irgendwie konstruieren läßt $\mathrm{t}^{\text {“411. }}$

In der Rue de Lille lagen die Nerven zusehends blank. Am 24. August entriß Epting der Louvre-Direktion die zugesagten Verzeichnisse, wobei er gedroht haben soll, die Kisten in den Bergungsorten gewaltsam öffnen zu lassen. Gefolgsleute Künsbergs traten anderenorts in ähnlich rüder Form auf den Plan. Ihr Vorwand: Die Franzosen zögerten die Herausgabe der Listen über Gebühr hinaus. „Dieses Vorgehen“, klagte General Streccius, „widersprach den getroffenen Vereinbarungen, hat bei den Franzosen den Eindruck einer Uneinigkeit innerhalb der Militärverwaltung erweckt und den naheliegenden Verdacht entstehen lassen, daß [...] andere Absichten als der Schutz der Kunstwerke zugrunde lägen." Graf Wolff Metternich, schnurstracks in den Louvre geeilt, stellte die Häscher zur Rede; er machte seiner Empörung Luft und sammelte die Listen wieder ein. Erst am 28. August wurden sie der Botschaft offiziell ausgehändigt ${ }^{42}$. Die Abetz zugeteilten Berliner Kunstexperten werteten sie unverzüglich aus und schufen binnen weniger Tage ein mit Fotografien angereichertes Inventar, in Künsbergs Worten

schrift für Brauchitsch vom 26. 9.1940 regte er an, mit dem „Erlös des von Juden und sonstigen Kriegsschuldigen beschlagnahmten Eigentums“ ein Winterhilfswerk für bedürftige Franzosen zu speisen. „Vorschlag zu einer Neuordnung des Gewerkschaftswesens und zu sozialistischen Maßnahmen im besetzten Frankreich", ebenda.

37 „Bargatzky-Bericht", S. 296.

38 Abetz an Ribbentrop, 22. 8. 1940; PA/AA, R 29587.

39 Unterstaatssekretär Habicht für Ribbentrop, 29. August; PA/AA, R 27623.

40 Goebbels, Tagebücher, I, 4, S. 298 (Eintrag vom 28. 8. 1940).

41 Aufzeichnung des AA-Vertreters Dr. Kolb „über die Sitzung im Promi betreffend französischen Kunstraub am 22. 8. 1940“; PA/AA, Botschaft Paris 1294. Vgl. Kurz, Kunstraub, S. 120f. Staatssekretär v. Weizsäcker notierte seinerzeit (21.7. 1940): „Man spricht jetzt viel von Repatriierung von Kunstwerken aus Frankreich. Ein Bekannter von mir geht noch weiter und nennt die Museen (wie den Louvre) die, Wanderpokale' für gewonnene Kriege. " Hill (Hrsg.), Weizsäcker-Papiere 1933-1950, S. 214.

42 "Bargatzky-Bericht“, S. 297; Metternich, "Über meine Tätigkeit“, pag. 16. Vgl. die Darstellung bei Kurz, S. $141 \mathrm{f}$. 
„ein anschauliches Bild dessen [...], was zu Ende des Krieges von Frankreich als Schadenersatz gefordert werden kann"43. „Die Herren Professoren wählen nunmehr die für Deutschland sicherzustellenden Kunstwerke aus“, notierte GFPKommissar Josef Gerum ${ }^{44}$. Abetz selbst spornte die Wissenschaftler an, einen repräsentativen Katalog zu fabrizieren, der - mit Minister-Typen geschrieben Hitler und Ribbentrop vorgelegt werden sollte ${ }^{45}$. Ein dicker Wermutstropfen aus Sicht der Botschaft war allerdings die Erkenntnis, „daß die besten Stücke des Louvre von den Franzosen im unbesetzten Gebiet in Sicherheit gebracht wurden"46.

Weitaus größerer ,Erfolg' war Abetz einmal mehr bei der Beschlagnahme jüdischen Kunstbesitzes beschieden. Am 24. August erwirkten Epting und Künsberg vom Chef des militärischen Verwaltungsstabes, Dr. Jonathan Schmid, die Genehmigung, unter Mithilfe der Geheimen Feldpolizei etwa 50 von ihren Bewohnern verlassene Häuser zu durchsuchen. Auch in diesem Fall beriefen sie sich auf einen angeblichen ,Führer'-Befehl. Schmids Auflage, Kunstgegenstände bei ausreichender Sicherung lediglich zu registrieren und am Fundort zu belassen, wurde offenkundig ignoriert ${ }^{47}$. Erneut türmten sich in der Botschaft „größere Bestände an jüdischem Kunstbesitz “48. Aus der Wohnung des früheren Ministers Mandel wurden am 27. August 14 Gemälde mitgenommen ${ }^{49}$. In den darauffolgenden Tagen machte die GFP üppige Beute auf Anwesen und Schloßgütern der Familie Rothschild ${ }^{50}$. Wie ergiebig sie war, erhellt Abetz' Wunsch, den Paris-Auftrag der Kolonne Künsberg noch einige Tage zu verlängern. Der Botschafter, hieß es, brauche die Männer "dringendst, um den neu beschlagnahmten jüdischen Kunst-

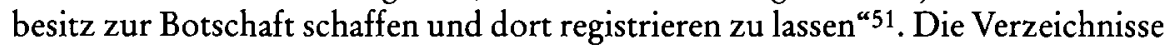
samt den „dazugehörigen Alben“ wollte Ribbentrop dem ,Führer' bei nächster

43 Aufzeichnung Künsberg vom 1. 11. 1940; PA/AA, R 27579.

44 Bericht vom 30. 8. 1940; PA/AA, R 27528.

45 Dr. Alfred Erb (Künsberg-Mitarbeiter) an seinen Chef, 28. August, ebenda.

46 Künsberg an Auswärtiges Amt, 27. August; ders. an Luther, 5. September; ebenda.

47 Vgl. „Bargatzky-Bericht“, S. 297f. Künsberg an Auswärtiges Amt, 27. 8. 1940; PA/AA, R 27578 .

48 Aufzeichnung Künsberg vom 1. 11. 1940; PA/AA, R 27579.

49 Bericht Gerum, wie Anm. 34.

50 Aufzeichnung Künsberg, wie Anm. 43. Zwei dickleibige Verzeichnisse bei den Botschaftsakten lassen Umfang und Sachwert erahnen. Anlage 2 des „Sonderbands jüdischer Kunstbesitz" (PA/AA, Botschaft Paris 2490) listet unter anderem Kostbarkeiten aus den Sammlungen Maurice Rothschild (allein 77 Seiten), Edmond Rothschild ("vorgefunden auf Schloß Ferrières") und James-Armand Rothschild auf. Ein „Verzeichnis der durch die Deutsche Botschaft sichergestellten Bilder und Kunstgegenstände" (PA/AA, Botschaft Paris 2495) enthält auf 263 von 287 Seiten Objekte aus Rothschild-Besitz. Sie wurden in den Gebäuden 80 und 82 rue de Lille und im Deutsch-Französischen Institut (57 rue St. Dominique) gelagert.

51 Luther an v. Dörnberg (Chef des Protokolls im AA), 9. 9. 1940 (Hervorhebung im Original); positiver Bescheid Halems an Luther vom 10. September; PA/AA, R 27579. Eine glatte Lüge Abetz' spätere Behauptung: „Künsberg et les membres de sa mission ne firent jamais leur apparition. Je suppose qu'ils avaient, entre temps, reçu l'ordre de se tenir prêts pour l'invasion de l'Angleterre." Verhörprotokoll Nr. 204/24 der Renseignements Généraux vom 26.11. 1945, „Rôle d'Abetz en ce qui concerne les réquisitions allemands d'œuvres d'art“, pag. 7; AN, F 7/15331 (= CDJC, LXXI-117). 
Gelegenheit vorlegen ${ }^{52}$. Bis Mitte September war die Arbeit erledigt und ,jeder Gegenstand mit Nummer und Namen des Voreigentümers [!] versehen" ${ }^{\text {"53. }}$.

\section{Schätze „aus vormals jüdischem Besitz“: Der dreiste Versuch, Unrecht zu sanktionieren}

Damit hatten Abetz' Aktivitäten ihren Zenit überschritten, denn in der Folge erwuchs ihm übermächtige Konkurrenz: Rosenberg und Göring sicherten sich per Führerentscheid den alleinigen Zugriff auf die jüdischen Kunstschätze Frankreichs. Der Einsatzstab des Reichsleiters, eine zivile, mit Parteigeldern finanzierte Organisation, hatte Anfang Juli den Auftrag erhalten, Staatsbibliotheken, Archive, Kirchenbehörden und Logen in den besetzten Westgebieten nach Material zu durchforsten, das für die politische Schulungsarbeit der NSDAP und den ngeistig-weltanschaulichen Kampf gegen die Ideologie des Westens" von Nutzen sei $^{54}$. Als Rosenbergs Leute bei ihren Nachforschungen auf „z. Zt. herrenlose“ jüdische Kunstsammlungen stießen, war der Appetit geweckt. Angeblich um die Gegenstände „vor Diebstahl, Vernichtung und Beschädigung zu schützen“, erlangte der NS-Ideologe Hitlers Placet, „ihm wertvoll erscheinende Kulturgüter nach Deutschland abzutransportieren und hier sicherzustellen"55. Die Worthülsen unterschieden sich ebensowenig von denen der Botschaft wie die notdürftig verbrämten Motive. Bis Juli 1944 konfiszierte der Einsatzstab, um einen „Sonderstab Bildende Kunst" erweitert, in Frankreich systematisch weit über $20000 \mathrm{Ge}$ mälde, Plastiken, Möbel, Gobelins und so fort. In Hunderten von Eisenbahnwaggons wurde die Beute ins Reich verschoben; als Sammellager in Paris dienten Räume des Louvre und der Jeu de Paume ${ }^{56}$. Wie fundamental die hierbei zutage tretenden Ansichten über Recht und Moral von denen der Militärverwaltung abwichen, belegt Chronist Bargatzky mit schlagenden Beispielen. „Die Erfassung des jüdischen Kunstbesitzes ist weder als Beschlagnahme kriegswichtigen Eigentums noch als polizeiliche Maßnahme im Interesse einer einheitlichen Bewirtschaftung des besetzten Gebietes zu bezeichnen", kommentierte ein Gutachten

52 Luther an Abetz, 10. 9. 1940; PA/AA, R 27623.

53 Halem an Luther, 13. September; PA/AA, R 27579.

54 Keitel an den Oberbefehlshaber des Heeres, Erlaß Hitlers vom 5. 7. 1940; PA/AA, Botschaft Paris 1321. Tätigkeitsbericht des Reichshauptstellenleiters Utikal, 20. 3. 1941, zit. im „Bargatzky-Bericht", S. $301 \mathrm{f}$.

55 Rosenberg an Best, 5. 9. 1940; Erlaß Keitels vom 17. September ("ergänzend zum 5. 7. hat Führer entschieden"); zit. ebenda, S. $305 \mathrm{ff}$.

56 Arbeitsbericht des Einsatzstabes Rosenberg vom Oktober 1940 bis Juli 1944, vorgelegt von Robert Scholz, zit. von Kurz, Kunstraub, S. 244 ff. Ausführlich zu dieser Thematik, auch zur unheiligen Allianz Rosenberg-Göring, die im Rahmen dieser Studie nur gestreift werden kann, ders., Kap. „Frankreich“; Nicholas, Raub der Europa, S. 170-190 und passim; Dorléac, L'art de la defaite, S. 23-30 und passim; Bollmus, Amt Rosenberg, S. $145 \mathrm{ff}$.; sowie die älteren Darstellungen Günther-Hornig, Kunstschutz, S. $24 \mathrm{ff}$.; Brenner, Kunstpolitik; Cassou (Hrsg.), Le pillage, S. $42 \mathrm{ff}$. Siehe ferner Wilhelm Alff, „Kunstreaktion - Kunstraub - Kunstterror. Die nationalsozialistische Kunstpolitik“, in: FAZ, 16. 11. 1963; „Bargatzky-Bericht ${ }^{\star}$, S. $301 \mathrm{ff}$. 
der Abteilung Justiz vom 29. Januar 1941. Im selben Monat ließ der Einsatzstab Rosenberg verlauten: „Wie mit den Heckenschützen, so gibt es auch mit den weltanschaulichen Feinden keinen Frieden auf moralischer Grundlage [...] Das Rembrandt-Bild von heute ist praktisch die Finanzierung des anti-deutschen Kampfes von morgen. Es fällt deshalb ebenso unter die materiellen Kriegsgüter, wie die Waffen des Soldaten ${ }^{4} 5$.

Nicht minder dreist verhielt sich Hermann Göring. Am 3. November 1940 plünderte er erstmals eine im Jeu de Paume eigens für ihn inszenierte Schau beschlagnahmter Kunstwerke, ein Vorgang, der sich in den kommenden Jahren dutzendfach wiederholte. Skrupellos verstand er es, den Einsatzstab Rosenberg vor seinen Karren zu spannen und Hitlers Zustimmung für ein kombiniertes Vorgehen in Frankreich einzuholen, bei dem sich der Reichsmarschall ungeniert für seine privaten Sammlungen bediente. Auch Spitzel und das Devisenschutzkommando, mit weitreichenden Vollmachten zur Kontrolle des französischen Geschäfts- und Bankenverkehrs ausgestattet, stöberten versteckte Schätze für den Unersättlichen auf; als Beauftragter des Vierjahresplans war Göring weisungsbefugt. Juristische Einwände der Militärverwaltung erklärte er für irrelevant: „Der höchste Jurist im Staate bin ich!“58 Resigniert stellte Militärbefehlshaber Otto v. Stülpnagel fest, daß sich solch völkerrechtswidriges Gebaren „angesichts des starken persönlichen Interesses der politischen Führung" nicht verhindern lasse. Er lehnte jede weitere Verantwortung ab: „Mein ganzes inneres Empfinden, mein rechtliches Denken und meine Auffassung von der notwendigen Haltung des Siegers im besetzten Gebiet wendet sich dagegen." Ein Satz, den er womöglich auch Otto Abetz ins Stammbuch geschrieben hätte, wäre diesem das ,Prä in Sachen Beutekunst nicht entzogen worden ${ }^{59}$.

Woher der Wind wehte, bekamen Abetz und Künsberg erstmals im September zu spüren. Die Rothschild-Palais konnten nicht restlos geräumt werden, weil Görings Mann in Paris, Fliegergeneral Hanesse, sie kurzerhand unter seine Kuratel stellte ${ }^{60}$. Wenig später drehte sich das Blatt vollends: Auf Anweisung aus Berlin mußte die Botschaft das Gros der bis dahin gehorteten Kunstwerke aus jüdischem Besitz an Rosenberg abtreten; die Objektdaten füllten zwei Kataloge von je annähernd 300 Seiten ${ }^{61}$. Der genaue Übergabetermin geht aus den Akten nicht hervor; vermutlich wurde der Transfer bereits im Herbst 1940 vollzogen. Ein Protokoll

57 „Bargatzky-Bericht“, S. 325f.

58 Zwei Schlüsseldokumente hierzu: Erlaß Görings vom 5.11. 1940, abgedruckt „Bargatzky-Bericht“, S. $312 \mathrm{f}$. Göring an Rosenberg, 21. November, ebenda, S. $313 \mathrm{ff}$. In diesem Brief nennt Göring die Zusammenarbeit „vorbildlich und außerordentlich zweckentsprechend“. Die Rollen waren verteilt: Dem ERR obliege es, „die Dinge zu erfassen und heranzuschaffen“, während seine eigenen Mittelsmänner beim Ausspähen von Verstecken behilflich sein sollten und die Luftwaffe Transportmittel und Wachpersonal stellte. Zum Devisenschutzkommando Günther-Hornig, Kunstschutz, S. $27 \mathrm{ff}$.

59 Stülpnagel an Brauchitsch, 31. 1. 1941, abgedruckt „Bargatzky-Bericht“, S. 328.

$60 \mathrm{Vgl}$. Halem an Luther, 13. 9. 1940; Zeitschel an Künsberg, 25. September; Bericht Gerum für Künsberg, 29. November; PA/AA, R 27579.

61 Geheimprotokoll (5 S. und Anlagen) mit den Unterschriften von Abetz und seinem Mitarbeiter Carltheo Zeitschel, 1. 2. 1941; PA/AA, R 27656. Jahresbilanz Zeitschels, 13. 6. 1941; PA/AA, Botschaft Paris 1321. 
vom Februar 1941 indes bestätigt: Die in die Rue de Lille verbrachten Schätze wurden mitnichten nur vor Kriegsfolgeschäden und Plünderungen geschützt oder im Hinblick auf friedensvertragliche Forderungen einbehalten, wie Abetz glauben machen wollte ${ }^{62}$. In Absprache mit Rosenbergs Leuten wurden vielmehr mindestens 74 ,in den Katalogen nicht vermerkte" Positionen ins Hausinventar der Botschaft „übernommen und damit in Reichsbesitz überführt"63. Darunter befanden sich Gemälde und Zeichnungen von Renoir, Fragonard und Degas, verschiedene Meister des 18. Jahrhunderts, acht Sessel Stil Louis XVI., alte Brüsseler Tapisserien und ein wertvoller Schreibtisch mit Aufsatz, einst ein Geschenk der französischen Regierung an Fürst Metternich, nach Recherchen des Auswärtigen Amts von Baron Edmond de Rothschild für umgerechnet 660000 Reichsmark erworben, jetzt von Abetz genutzt. $\mathrm{Daß}$ die Botschaft das edle, in Fachpublikationen erwähnte Stück lediglich auf $5000 \mathrm{RM}$ taxierte, könnte ein Indiz für betrügerische Absichten sein, beruhte aber vielleicht auch schlicht auf Banausentum. Die Verwaltungsabteilung des AA wies mit spöttischem Unterton darauf hin, „daß Herr Botschafter Abetz den Aufsatz des Schreibtisches entfernt hat und verkehrt vor demselben sitzt, um das Licht von links zu haben; der Schreibtisch wirkt daher in seiner gegenwärtigen Aufstellung als Torso"64.

25 Gemälde und Zeichnungen aus dem Botschaftsdepot wurden „zur Ausstattung des Auswärtigen Amts und des Hauses des Herrn Reichsaußenministers in Betracht gezogen" und nach Berlin geschickt; mehrere Fragonards, Bouchers, Watteaus und Utrillos wechselten auf diese Weise von der Seine an die Spree65. Ein Schreiben Luthers belegt, daß 15 Gemälde im AA verblieben; verschmäht und nach Paris zurückgeschickt wurden unter anderem ein Degas und ein Monet ${ }^{66}$. Weitere 26 Bilder „entarteter" Maler - darunter 14 Braques und sieben Picassos hat die Botschaft "für den Umtausch gegen künstlerisch wertvolle Werke" auf dem Kunstmarkt einbehalten ${ }^{67}$. Im August 1941 drängte Legationsrat Zeitschel, die "wild expressionistischen Bilder" schleunigst abzustoßen, ehe der Einsatzstab Rosenberg den Markt mit seinen ungleich größeren Beständen überschwemme ${ }^{68}$.

In der Version Schleiers hört sich das alles vergleichsweise harmlos an: Sowohl das Auswärtige Amt als auch die Botschaft Paris hätten besagte Objekte „treuhänderisch" übernommen, einige einstweilen in den Diensträumen aufgehängt und sie nach Kriegsende käuflich erwerben wollen ${ }^{69}$. Doch waren die rechtmäßigen

62 Vgl. vierseitige Aufzeichnung zum Vorwurf des Kunstraubs, während der U-Haft angefertigt, im Nachl. Schleier/III.

63 Geheimprotokoll vom 1. 2. 1941, pag. $2 \mathrm{ff}$.

64 Gesandter Schwager an Luther, 22. 10. 1942; PA/AA, R 27656. Vorausgegangen war eine Anfrage des Staatssekretärs v. Weizsäcker zur Rechtslage im Hinblick auf die einbehaltenen Kunstwerke.

65 "Annex zum Protokoll über die Sicherstellung des jüdischen Kunstbesitzes vom 1. 2. 41“ mit „Aufstellung der Gemälde, die sich im Hause Wilhelmstraße 73 befinden“; PA/AA, R 27656.

66 Luther an Botschaft Paris („zu Händen von Herrn Dr. Epting“), 8. 11. 1940; CDJC, LXXI-43.

67 "Annex“ mit Anlage 4.

68 Zeitschel, Aufzeichnung für Abetz, 11. 8. 1941; CDJC, V-101.

69 PA/AA, Nachl. Schleier/IV.2., Nr. 11: „Kunstraub?“, pag. 9. 
Eigentümer weder um ihr Einverständnis gefragt worden, noch war ihnen ernsthaft eine Entschädigung zugedacht. Die amtlicherseits bevorzugte Lesart, ihre Sammlungen würden bei Friedensschluß gegen französische Reparationen verrechnet, variierte Otto Abetz dergestalt, daß er das Geld in einen Fonds für Kriegsopfer stecken wollte. Auf die Frage eines amerikanischen Vernehmungsbeamten, worauf sich denn „die Enteignung der Eigentümer" stützte, nannte er den Versailler Vertrag; mit ihm sei diesbezüglich ein „Präzedenzfall" geschaffen worden $^{70}$. Wieviel ideologische Verblendung im Spiel war, zeigt die nach 1945 aufrechterhaltene Begründung, „daß die Juden die Schuld am Kriegsausbruch trügen und sie daher auch für die Schäden, die ihre Landsleute in Frankreich erlitten hatten, aufkommen müßten"71.

Diese Argumentation deckt sich mit einem Vorschlag, den Abetz im Februar 1941 dem Beauftragten des Chefs der Sicherheitspolizei und des SD in Paris, SSBrigadeführer Dr. Thomas, unterbreitete. Sicherstellung und Verwaltung des jüdischen Kunstbesitzes sollten fortan dem zu schaffenden "Zentralen Judenamt “ obliegen, und wer immer die dort erfaßten Objekte „erwarb“, sollte den „regulären Kaufpreis“ entrichten. Mit den Erlösen wollte der Botschafter das Judenamt finanzieren und bedürftige französische Familien unterstützen. „Propagandistisch würde die Aktion wirksam unter dem Gesichtspunkt, dass die Juden als hauptsächlichste Kriegsschuldige mit ihrem Eigentum den Kriegsopfern helfen." Vielleicht trachtete Abetz auch danach, Rosenberg und Göring den privilegierten $\mathrm{Zu}$ griff auf die Beutekunst wieder streitig zu machen. Seinem Vorstoß war jedoch kein Erfolg beschieden 72 .

Im Mai 1941 sprach Abetz von Plänen, die für Ribbentrop bestimmten Gemälde schätzen zu lassen; die Summe solle an eine noch zu bestimmende Stelle gezahlt werden. Etwa um die gleiche Zeit verfolgte auch Legationsrat Zeitschel die Idee, Einnahmen aus dem Verkauf jüdischer Kunstschätze in das „Zentral-Juden$\mathrm{amt}^{\text {“ }} \mathrm{zu}$ stecken ${ }^{73}$. Als aber Ribbentrops Büro die Pariser Botschaft ersuchte, Preise und mögliche Empfänger zu nennen, notierte Zeitschel auf den Rand des Telegramms: „nach neuerer Weisung Luther [...] nicht mehr nötig“74. 14 Monate später bekannte Schleier: „Die Rechtslage betreffend den gesamten beschlag-

70 Vernehmung Abetz' durch M. Orthmann am 6. 7. 1948, pag. 20; StA Nürnberg, KV-Anklage, Interrogations, A 2. An anderer Stelle präzisierte er: für französische Kriegsopfer; Verhörprotokoll Nr. 204/24, pag. 5; AN, F $7 / 15331$ (= CDJC, LXXI-117). Auch vor Gericht wies Abetz darauf hin, der Versailler Vertrag habe die Konfiszierung deutschen Privatvermögens zugelassen. Abetz-Prozeß, 15. 7. 1949, pag. 44; AN, 334 AP 49. Schleier beanstandete in seinem „Kunstraub“-Memorandum (siehe oben) die Artikel 245 und 247.

71 Abetz, Aufzeichnung zum Vorwurf des Kunstraubs; PA/AA, Nachl. Schleier/III.

72 Abetz an Thomas, 20. 2. 1941. Der Verf. ist Serge Klarsfeld (Paris) zu Dank verpflichtet, der das Dokument aus seinem Archiv zur Verfügung stellte. Der Begriff „Zentrales Judenamt" meinte das auf deutsches Drängen im März 1941 vom französischen Ministerrat etablierte Generalkommissariat für Judenfragen (Commissariat Général aux Questions Juives, siehe unten).

73 "Notiz für Herrn Botschafter Abetz" mit Zeitschels Paraphe; CDJC, V-17. Ein Datum fehlt, die zeitliche Zuordnung ergibt sich aus dem Inhalt.

74 Schwarzmann (Büro RAM) an Botschaft Paris, 28. 5. 1941; CDJC, LXXI-59. 
nahmten jüdischen Kunstbesitz ist m.[eines] W.[issens] noch nicht geklärt. "75 Die Rechtsabteilung des AA sanktionierte schließlich das Unrecht, indem sie empfahl, den „Begriff der Sicherstellung, der nur über die vorläufige Verwendung entscheide", zu meiden und hinsichtlich der in der Botschaft verbliebenen Objekte lieber von Kunstwerken „aus vormals jüdischem Besitz" zu sprechen ${ }^{76}$. Wie blanker Zynismus mutet in diesem Kontext das Votum der Juristen an, einzelne sehr bekannte Kunstwerke nicht länger in der Rue de Lille zur Schau zu stellen, sondern sie „aus Gründen des Taktes“ nach Deutschland zu transportieren77. Fern der Realität, aus Erklärungsnot geboren, Abetz’ Einlassung vor Gericht: „A mon avis, le transfert d'un œuvre d'art d'un territoire occupé dans le pays vainqueur ne précise encore rien." 78

Daß die Botschaft bei Gelegenheit auch dann noch jüdischem Kunstbesitz nachjagte, als Rosenberg diesen Auftrag bereits an sich gerissen hatte, dokumentiert der Raub der nahe Bordeaux versteckten Bilder Paul Rosenbergs, im Urteil Kurz' „die wohl wertvollste Privatsammlung moderner französischer Malerei überhaupt "79. Gleich von zwei Seiten wurde sie im Herbst 1940 an die Deutschen verraten. Karl Epting zahlte einem gewissen Jurschewitz 65000 Francs - „gewissermaßen als Judaslohn“ - für eine Adresse ${ }^{80}$. Auch der Comte de Lestang und sein Komplize Yves Perdoux lieferten entscheidende Informationen, die zur Aushebung der Depots führten. Sie verlangten zehn Prozent Provision und schätzten die Sammlung auf zwei Milliarden Francs - in Zeitschels Augen eine „Unverschämtheit", kam doch ein deutscher Fachmann allenfalls auf 3,4 Millionen ${ }^{81}$. Das vereitle ,jegliche vernünftige Zusammenarbeit", rüffelte der Legationsrat die beiden Spitzel. Sie schwenkten nach längerem Feilschen in etwa auf die deutschen Vorstellungen ein. Bei einer Besichtigung der beschlagnahmten Sammlung forderten sie als Bezahlung zwei Pissaros und ein Akt-Bild von Renoir. Zeitschel empfahl statt des letzten Objekts einen dritten, „doppelt so wertvollen" Pissaro; da dieser Jude sei, ,nehme ich an, daß in Deutschland für diese Bilder kein Interesse

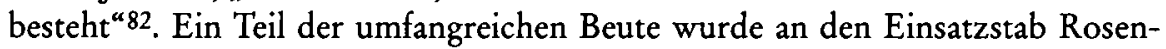

75 Schleier an Auswärtiges Amt, 31. 7. 1942; IMT, NG-2970, mit Vermerk Weizsäckers vom 10. August: „Ich nehme an, daß Abt. Pers in Verbindung mit Abt. D die Rechtslage [...] prüft und die Frage zu einem Abschluß bringt."

76 Schwager an Luther, 22. 10. 1942. Die Botschaft hat diese Sprachregelung nachweislich übernommen. Vgl. Schleier an AA, 3. 5. 1943; Abetz an AA, 29. 2. 1944; PA/AA, R 27656. Schlicht unwahr Abetz' spätere Aussage, die Eigentumsrechte seien weder von seiten der Botschaft noch vom Auswärtigen Amt jemals in Frage gestellt worden. Verhörprotokoll Nr. 204/24, pag. 4; AN, F 7/15331.

77 Schwager an Luther, 22. 10. 1942. Luther teilte hierzu am 2.11. 1942 mit, Ribbentrop behalte sich die Entscheidung über den schlußendlichen Verbleib der Objekte „ausdrücklichst" vor; PA/AA, R 27656.

78 Abetz-Prozeß, 15. 7. 1949, pag. 53; AN, 334 AP 49.

79 Kurz, Kunstraub, S. 145.

80 Zeitschel, Aufzeichnung für Schleier, 24. 11. 1941; CDJC, V-106.

81 Zeitschel, Aufzeichnung für Abetz, 27. 11. 1940; CDJC, V-98. Eine beigefügte Schätzliste enthält 21 Bilder von Picasso, 20 von Braque, sechs Matisse, vier Renoir und etliches mehr.

82 Zeitschel, Aufzeichnung für Abetz, 28. November; CDJC, V-104. 
berg abgetreten, der „entartete“ Rest zu Tauschzwecken in der Rue de Lille gehortet $^{83}$.

Begehrlichkeiten weckte auch die von 1942 an in großem Stil betriebene Beschlagnahme jüdischer Wohnungseinrichtungen, zunächst im besetzten Teil Frankreichs. Von Rosenbergs Leuten ausgeräumt, wurden tausende Tonnen Möbel an Besatzungstruppen im Osten und ausgebombte Familien im Reich verteilt. In die Vorbereitungen dieser „M-Aktion“ schaltete sich Otto Abetz, gerade auf Reisen, mit dem telegraphisch übermittelten Ratschlag ein, die Vichy-Regierung vorab besser nicht einzuweihen, ,weil formaljuristisch keine Rechtsgrundlage für Maßnahme vorhanden. Empfehle geschichtliche Berechtigung [...] in dem vom nationalsozialistischen Deutschland gegen die Juden geführten Krieg dadurch zu begründen, daß Verwendung beschlagnahmter Einrichtungen zugunsten Wiederaufbaus der im Osten vom jüdischen Bolschewismus zerstörten Gebiete in geplanter Presseveröffentlichung Militärbefehlshabers stark hervorgehoben wird." 84 Legationsrat Zeitschel regte eine Sammelbestellung des Botschaftspersonals für jüdisches Mobiliar an, sobald es registriert und zum „Reichseigentum erklärt" sei85.

Der nationalsozialistische Kunstraub wirft tiefe Schatten auf Otto Abetz' Person, um so mehr, als er studierter Kunstkenner war und die Kunst als seine „entscheidende Brücke zu Frankreich" bezeichnete ${ }^{86}$. Sein Ringen mit der Militärverwaltung, vordergründig ein frühes Kräftemessen um politischen Einfluß im besetzten Paris, gibt den Blick frei auf knallharte Präferenzen ${ }^{87}$. Sobald es gegen erklärte Reichsfeinde ging, deren Schicksal ihm für die deutsch-französische Zukunft bedeutungslos erschien, gebärdete sich der selbsternannte Bremser Hitlerscher Brachialgewalt selbst als unbarmherziger NS-Ideologe. Als „Doppelnatur“ hat ihn Kunstraub-Chronist Walter Bargatzky beschrieben: innerlich gewissen bürgerlichen Werten verhaftet und zugleich erpicht, sich Vorgesetzten gegenüber als genügend stramm zu erweisen; zwischen Parteiraison und persönlichen Sympathien schwankend; charakterlich durchaus labil, nun aber vor dem Problem, mit einer unversehens erlangten Machtposition zurechtzukommen ${ }^{88}$. Daß er seinen Platz verteidigen und ,in der Wirkung viel tiefgreifendere Maßnahmen“ anderer Dienststellen verhindern wollte ${ }^{89}$, schmälert - unabhängig von der Glaubwürdigkeit - nicht das Verwerfliche mancher Tat. Doch war es im Lichte dieser Logik keineswegs nur absurd - wie Schleier meinte -, daß ein „überzeugter Verfechter

83 Zur Beschlagnahme der Sammlung Rosenberg siehe auch Kurz, Kunstraub, S. $145 \mathrm{ff}$.; Nicholas, Raub der Europa, S. 176; Cassou, Pillage, S. $56 \mathrm{ff}$. und Dokumentenanhang.

${ }^{84}$ Abetz (z. Zt. Sonderzug) an Botschaft Paris, 31.1. 1942; ADAP, E I, S. 346, Anm. 6. Zuvor Schleier an Auswärtiges Amt, 30. Januar, ebenda, Nr. 187. Ausführlich zur „M-Aktion" Kurz, Kunstraub, S. $221 \mathrm{ff}$.

85 Zeitschel für Kanzler Gerigk, 12. 3. 1942; CDJC, V-119.

86 Vernehmung durch M. Orthmann, 6. 7. 1948, pag. 18; StA Nürnberg, KV-Anklage, Interrogations, A 2.

87 Bezeichnend seine Einlassung vor Gericht, „que l'histoire des Juifs et des œuvres d'art juives n'est pas la plus importante“. Abetz-Prozeß, 15. 7. 1949, pag. 41; AN, 334 AP 49.

88 Schriftliche Mitteilung an den Verf. vom 8. 7.1991.

${ }^{89}$ Das beteuerte auch Schleier. Aufzeichnung, als Anlage einem Brief an Abetz vom 19.7. 1957 beigefügt; PA/AA, Nachl. Schleier/I.6. 
des Verständigungsgedankens“ just in dem Land, „dessen Freundschaft er sucht“, jüdisches Eigentum plünderte ${ }^{90}$. Völlig abwegig hingegen war der Anspruch, unter solchen Vorzeichen eine konstruktive Mittlerrolle zu spielen. Die praktischen Auswirkungen Abetzscher Politik gerieten so immer von neuem in unauflöslichen Widerspruch zu den behaupteten Motiven, ein Gegensatz, der seiner phantasievollen Apologetik trotzt. Nirgends wird dies deutlicher als in seiner Haltung gegenüber der jüdischen Bevölkerung Frankreichs.

\section{3. „Erbitte antisemitische Sofortmaßnahmen“: Judenfeindliche Politik und Propaganda}

Stets einen bildhaften Vergleich parat, bemühte Otto Abetz nordamerikanische Indianer, um seine Rolle bei der ,Endlösung der Judenfrage ${ }^{c}$ zu schildern. Angesichts des in Deutschland herrschenden Fanatismus habe er einen Kniff der Rothäute kopiert, denen Weiße mit Feuersbrünsten zu Leibe rückten: „Die Indianer haben damals selbst einen Streifen in der Prärie angezündet, um auf diese Weise das große Feuer, das sie bedrohte, abzuwenden. Das war die Methode, die ich in Frankreich anwendete." 91

Die Parabel illustriert beiläufig, wie Ribbentrops Zögling, durch eine höchst unkonventionelle diplomatische Schule gegangen, sein Handwerk verstand: Auf Direktiven zu warten, war seine Sache nicht. Er bevorzugte den aktiven Part, wollte Entwicklungen beeinflussen, eigene Vorstellungen verwirklichen. Der angebliche Versuch, die Feuerwalze des Holocaust durch vorbeugende Brandstiftung einzudämmen, paßt überdies zu seiner Verteidigungslinie vor Gericht, wonach mit den Wölfen heulen muß, wer sie überlisten will. Doch im Spiegel der Akten zählt die Botschaft Paris eher zu den Schrittmachern der europaweit anlaufenden Verfolgung, als daß sie Entrechtung und Deportationen gebremst hätte. Abetz dürfte hierbei einmal mehr der Ehrgeiz getrieben haben, sich als eigenständige, trotz Kollaborationskurs weltanschaulich zuverlässige Kraft in Paris zu etablieren. Von der Kriegsschuld der Juden war er in jedem Fall überzeugt, was sie in seinen Augen harter Strafe preisgab. Ernst Achenbach erklärte dazu sinngemäß, man habe antijüdische Maßnahmen mitgetragen, weil sie unter Hitler ein „religiöses Dogma" gewesen seien und man sich nicht durch Verweigerung Möglichkeiten verbauen wollte, auf anderen Gebieten Vernünftiges zu leisten ${ }^{92}$. Wie weit die Komplizenschaft letztlich reichte, erhellt ein Urteil des SS-Obersturmführers Theodor Dannecker. Der Leiter des SD-Judenreferats in Frankreich, ein wüster Antisemit, zollte den Diplomaten der Rue de Lille uneingeschränkten Respekt für ihre „wirklich umfassende, kameradschaftliche Unterstützung unserer Arbeit“93.

90 Schleier, „Kunstraub?“, pag. 1; ebenda, IV.2.

91 Vernehmung durch John Fried, 28. 5. 1947; StA Nürnberg, KV-Anklage, Interrogations, A 2.

92 Protokoll eines Gesprächs mit Robert Kempner in Nürnberg, 19. 8. 1947; ebenda, A 6.

93 Dannecker, „Judenfragen in Frankreich und ihre Behandlung“, pag. 70, vom 1.7. 1941; IMT, RF-1207. 
Mit Hitler, so Abetz, habe er nur einmal über die Judenfrage gesprochen, am 3. August 1940 in Salzburg. „Er sagte mir, er wolle die Judenfrage für Europa generell lösen, [...] indem er den besiegten Ländern zur Bedingung stellte, daß sie ihre jüdischen Staatsangehörigen außerhalb Europas verbringen. Ebenso wolle er auf die verbündeten Staaten einwirken. Er erwähnte in diesem Zusammenhang die Vereinigten Staaten von Amerika als ein Land, das lange nicht so übervölkert sei wie Europa und daher in der Lage, noch mehrere Millionen Juden aufzunehmen. "94 Tatsächlich hatten Pläne einer Massenaussiedlung aus dem großdeutschen Herrschaftsraum in ein überseeisches Reservat im Sommer 1940 Konjunktur. Am 11. Juli notierte Hans Frank nach einer Unterredung beim ,Führer', geplant sei, „die ganze Judensippschaft [...] in eine afrikanische oder amerikanische Kolonie zu transportieren. Man denkt an Madagaskar, das zu diesem Zweck von Frankreich abgetreten werden soll.“ Das Auswärtige Amt prüfte Möglichkeiten, vier Millionen Juden auf die Insel im Indischen Ozean abzuschieben ${ }^{95}$. Ein Projekt, das sich als utopisch erwies und verworfen wurde, indes noch längere Zeit in den Köpfen spukte und wohl auch in die ersten antijüdischen Initiativen der Botschaft Paris hineinspielte.

Es war Otto Abetz, der die Judenfrage im besetzten Frankreich - ohne erkennbaren äußeren Druck - als erster aufwarf. Die antisemitische Stimmung im Land sei so stark, konstatierte er in seiner Denkschrift vom 30. Juli 1940, „daß sie von unserer Seite keiner Förderung mehr bedürfte ${ }^{\text {96. }}$. Diese Formulierung, beteuerte er später, sollte „den Drang der Partei“ zügeln, im okkupierten Gebiet unverzüglich radikale Schritte gegen die jüdische Bevölkerung einzuleiten. Er habe „diese Dinge“ lieber der französischen Regierung überlassen wollen, von der er annahm, daß sie weniger rigoros verfahren werde 97 . Vichy war soeben aus eigenem Antrieb aktiv geworden: Per Sondergesetz vom 22. Juli 1940 wurde eine Regierungskommission geschaffen, die sämtliche Einbürgerungen der vergangenen Jahre überprüfte und am Ende mehr als 6000 Juden denaturalisierte ${ }^{98}$. Bald folgten weitere Dekrete, die einen historisch tiefverwurzelten Antisemitismus der französischen

94 Abetz, „Eidliche Erklärung“ vom 30. 5. 1947, pag. 5; CDJC, LXXI-123 (= IMT, NG1838). Desgleichen IMT, KV-Prozesse, A 97, Verhör am 2. 7. 1948, pag. 10914. Diese Darstellung deckt sich mit dem, was Abetz wenige Tage nach der Audienz Luther erzählte: Hitler „beabsichtige, nach dem Kriege sämtliche Juden aus Europa zu evakuieren“. Luther an Rademacher, 15. 8. 1940; ADAP, D X, Nr. 345.

$95 \mathrm{Vgl}$. Aly/Heim, Vordenker der Vernichtung, S. $257 \mathrm{ff}$., das Frank-Zitat auf S. 259; Döscher, Auswärtiges Amt, S. $215 \mathrm{ff}$.; Klarsfeld, Vichy-Auschwitz, S. 37 f; Hillgruber, Hitlers Strategie, S. $242 \mathrm{ff}$.; Reitlinger, Endlösung, S. $86 \mathrm{ff}$.; Hilberg, Vernichtung, 2, S. 416f.; Safrian, Eichmann-Männer, S. 93 ff. Legationssekretär Rademacher (AA/Abt. Deutschland) hat Einzelheiten des Madagaskar-Plans in einer Aufzeichnung "Die Judenfrage im Friedensvertrage" vom 3. 7. 1940 entwickelt; ADAP, D X, Nr. 101.

96 "Politische Arbeit in Frankreich"; CDJC, LXXI-28, pag. 6.

97 "Eidliche Erklärung" vom 30. 5. 1947, pag. 3. Desgleichen Abetz-Prozeß, 15. 7. 1949, pag. 72; AN, 334 AP 49. Siehe ferner die Aufzeichnung „Aktivität der Botschaft Paris in Judenfragen“, angefertigt von Klaus Mathy, Verteidiger-Assistent beim Militärtribunal IV in Nürnberg, aufgrund von Gesprächen mit Abetz, o.D.; PA/AA, Nachl. Schleier/I.17.

98 Vgl. Webster, Petain's Crime, S. 63; Jäckel, Frankreich, S. $99 \mathrm{f}$. 
Rechten spiegeln, neu angefacht durch Niederlage und Flüchtlingsströme ${ }^{99}$. So wurde Ende August das Verbot antisemitischer Propaganda aufgehoben und am 3. Oktober ein "Judenstatut" erlassen, das erstmals das Prädikat "Rasse" statt ${ }_{n}$ Religionsgemeinschaft" verwendete und Menschen israelitischen Glaubens den Zugang zu öffentlichen Ämtern, freien und künstlerischen Berufen verwehrte. Tags darauf wurden die Präfekten ermächtigt, ausländische Juden im unbesetzten Frankreich in Lagern zu internieren ${ }^{100}$.

Abetz' Stellungnahme vom 30. Juli entbehrte also nicht jeglicher Grundlage. Generell schonen mochte er die Juden aber keineswegs, wie eine andere Passage des Memorandums zeigt: Damit „die Trägerin des französischen Staatsgefühls, die Bourgeoisie, rücksichtslos ausgerottet" werde, empfahl er, „politische und intellektuelle Kriegshetzer“ zu enteignen. „Unter den Begriff der Kriegsschuldigen kann je nach Notwendigkeit jeder Parlamentarier, jeder Freimaurer, jeder Jude, jeder Kleriker und Journalist gefaßt werden, da von sämtlichen [...] Beschlüsse und Äußerungen zur Befürwortung und Verlängerung des Krieges vorliegen."101 Mit der Beschlagnahme von Kunstschätzen aus jüdischem Besitz hatte Abetz bereits selber einen Anfang gemacht. Auch sein politischer Ratgeber Friedrich Grimm ließ ideologisch fundierten Judenhaß erkennen: „Unsere Feinde sind: a) die Geistlichkeit beider Konfessionen, b) die Juden, c) der größte Teil der bürgerlichen Oberschicht, der verjudeten, korrumpierten Advokaten und Politiker“, resümierte er seine Gespräche mit Franzosen - „zum Teil erprobten Freunden“ - und warnte: „Die Juden sind nicht alle geflüchtet. Sie haben überall ihre Leute zurückgelassen, die schon wieder beginnen, den Widerstand zu organisieren."102

Die für Abetz charakteristische Gemengelage aus offensiven Forderungen und vorgeblicher Schadensbegrenzung verdichtete sich nach seiner Ernennung zum Botschafter. Bei einer Unterredung mit Ministerialdirektor Dr. Werner Best, dem starken Mann im Verwaltungsstab des „Majestic“, der in Berlin jahrelang die Judenpolitik der Sicherheitspolizei entscheidend beeinflußt hatte ${ }^{103}$, regte er am 17. August an, die Militärverwaltung möge ab sofort keine Juden mehr ins besetzte Gebiet hineinlassen, die „Entfernung“ aller dort lebenden Israeliten vorbe-

99 Zur Geschichte des Antisemitismus in Frankreich siehe die Literaturangaben in der Encyclopaedia Judaica.

100 Vgl. Marrus/Paxton, Vichy et les Juifs, S. 3 ff.; Webster, Petain's Crime, S. 60 ff. Kempner, Eichmann, S. 348 f., schreibt das Internierungsgesetz dem Druck der Deutschen Botschaft zu, ohne Belege zu nennen. Abetz selber hob in seinem „Tätigkeitsbericht 14. Juni 1940-14. Juni 1941“ (pag. 7) hervor, die Botschaft habe „beim Militärbefehlshaber und der französischen Regierung den Anstoß zur Judengesetzgebung gegeben“; PA/AA, $\mathrm{R}$ 102960. Seine Jahresbilanz ist naturgemäß vom Bemühen diktiert, Aktivitäten und Erfolge der Botschaft nach Kräften herauszustellen, doch sind Wechselwirkungen zwischen judenfeindlichen Initiativen der deutschen Besatzer und Vichys kaum von der Hand zu weisen.

101 "Politische Arbeit in Frankreich“, pag. $9 \mathrm{f}$.

102 "Grimm, „Eindrücke und Anregungen“, 19.6. 1940, pag. 6f., auch dem Verwaltungsstab des Militärbefehlshabers zugestellt; AN, AJ 40/539.

103 Vgl. Herbert, Best, S. 254 f. 
reiten und prüfen, ob sie enteignet werden könnten ${ }^{104}$. Drei Tage später erbat er Ribbentrops Einverständnis für "antisemitische Sofortmaßnahmen“, die den Boden für künftige Ausweisungen auch aus dem unbesetzten Frankreich bereiten sollten. Juden, so Abetz, müßten unbedingt daran gehindert werden, die Demarkationslinie nach Norden zu passieren; im besetzten Landesteil sollten sie meldepflichtig sein und alle Geschäfte und Betriebe, deren Besitzer geflohen waren, Treuhändern unterstellt werden. Die Maßnahmen, die von französischen Behörden ausgeführt werden sollten, ließen sich mit Sicherheitsinteressen der deutschen Truppen rechtfertigen ${ }^{105}$.

Das Berliner Ministerbüro antwortete postwendend, über die Vorschläge, denen man "hier günstig gegenübersteht", werde höheren Orts entschieden ${ }^{106}$. Am 29. August erfuhr Best aus Abetz' Mund, daß Hitler sie gutheiße und befohlen habe, „beschleunigt“ ans Werk zu gehen ${ }^{107}$. Verwaltungsfachleute des „Majestic" hatten den Forderungskatalog zwischenzeitlich schon unter besatzungspolitischen Gesichtspunkten geprüft. Sie gaben zu bedenken, daß systematische Schritte gegen die Juden im besetzten Frankreich auf deutsche Annexionsabsichten hindeuten könnten, ein Eindruck, der nach den Arbeitsrichtlinien der Militärverwaltung zu vermeiden war ${ }^{108}$. Auch wurde - wie schon beim Streit um die Kunstschätze - moniert, plumpe Enteignung verletze internationales Recht. Insgesamt aber stützten die Stellungnahmen Abetz' Ideen. Die Militärverwaltung dürfe nicht auf Dauer passiv bleiben, hieß es; sie müsse vielmehr das Fernziel deutscher Politik im Auge behalten, „in allen Bereichen des öffentlichen Lebens, einschließlich der Wirtschaft, den jüdischen Einfluß radikal auszumerzen“. Ausweisungen und Rückkehrverbot könnten unschwer mit der Sicherheitslage begründet werden - die feindselige Haltung der Juden sei offenkundig und darauf angelegt, die deutsche Kriegführung zu hintertreiben. Um den Anschein eines allzu methodischen Vorgehens zu vermeiden, wurde eine Vielzahl von „Einzelmaßnahmen" empfohlen, während Arisierungen "nach außen hin den Formen privatrechtlicher Übereignung folgen" sollten ${ }^{109}$.

104 Vermerk Best vom 19. 8. 1940; AN, AJ 40/548. Abgedruckt Klarsfeld, Vichy-Auschwitz, S. 356.

105 Abetz an Ribbentrop, 20. 8. 1940; ADAP, D X, Nr. 368.

106 Sonnleithner an Abetz, 21. August, ebenda, Anm. 1.

107 Aktenvermerk Best, 30. August; AN, AJ 40/548. Hitler stimmte vermutlich am 26 . August zu. Unter diesem Datum notierte Halder: „Führer wünscht Juden nicht über Demarkationslinie ins besetzte Gebiet zu lassen. Paßkontrolle." Halder, Kriegstagebuch, II, S. 77. Laut Best äußerte Abetz auch bei dieser Gelegenheit den Gedanken, Erlöse aus veräußertem jüdischem Vermögen gegebenenfalls für Fürsorgemaßnahmen zugunsten der französischen Bevölkerung zu verwenden.

108 Die einschlägige Passage zit. bei Umbreit, Militärbefehlshaber, S. 261: „Allein auf den Umstand, daß ein Landesbewohner Jude ist, dürfen Sondermaßnahmen gegen ihn vorläufig nicht gestützt werden."

109 Die Standpunkte sind summarisch wiedergegeben. Vgl. Vermerk Mahnke (Gruppe 1: Allgemeine und innere Verwaltung), 22. 8. 1940; Bargatzky (Gruppe 8: Justiz), 26. August; Bardenheuer (Gruppe 2: Polizei), 27. August; Storz (Abteilung Wirtschaft), o.D. Sämtliche Dokumente AN, AJ 40/548. Die Stellungnahmen von Mahnke und Storz sind abgedruckt bei Klarsfeld, Vichy-Auschwitz, S. 356 ff.; Storz' Ausführungen werden dort jedoch irrtümlich Abetz zugeschrieben. 
Best beauftragte daraufhin die Verwaltungsgruppe Polizei, gemeinsam mit den Rechts- und Wirtschaftsexperten des „Majestic“ juristische Handhaben zu formulieren; sie wurden Mitte September vom Oberbefehlshaber des Heeres gebilligt ${ }^{110}$. Heraus kamen zwei „Verordnungen über Maßnahmen gegen Juden“ vom 27. September und 18. Oktober 1940, die den Forderungen des Botschafters vollständig Rechnung trugen ${ }^{111}$. In Abetz' Lesart nach Kriegsende waren sie geeignet, das jüdische Los zu erleichtern. Denn angeblich drohte Frankreich im Sommer 1940 eine NS-Sonderbehörde mit unbegrenzten Vollmachten und eigenen Exekutivkräften, die mit sattsam bekanntem Fanatismus gegen die Juden vorgegangen wäre. Um eine solche Dienststelle zu verhindern, hätten Botschaft und Militärverwaltung gemeinsam die Initiative ergriffen und „Mindestvorschläge“ unterbreitet, die von hinreichender antijüdischer Gesinnung zeugen und zugleich Schlimmeres verhüten sollten. „Ich dachte, daß sie [die Juden] auf diese Weise besser herauskämen." 112

Diese Version hält kritischer Betrachtung nicht stand. Das Zusammenspiel von Botschaft und Militärverwaltung bewirkte vielmehr die bis dahin einschneidendsten antijüdischen Maßnahmen in den eroberten Gebieten West- und Nordeuropas und hatte Signalfunktion für andere deutsche Besatzungsregimes ${ }^{113}$. Darüber hinaus rief Abetz' Vorstoß eben jene ,Falken' auf den Plan, die er angeblich fernhalten sollte. Reinhard Heydrich, Chef des Reichssicherheitshauptamts, begrüßte seine Ideen, erachtete allerdings „eine weitgehende Einschaltung des Pariser SipoKommandos, das gerade auf dem Judengebiet über sacherfahrene Kräfte verfügt, für unerläßlich "114. Ein OKW-Erlaß übertrug daraufhin am 4. Oktober 1940 dem in der Avenue Foch residierenden Befehlshaber der Sicherheitspolizei und des SD (BdS), Helmut Knochen, die „Behandlung der Judenangelegenheiten“115 - eine Direktive, die Knochens zunächst recht bescheidene Stellung vor Ort mächtig aufwertete. Ähnlich wie die Goebbels-Propagandisten gehörten der 30jährige SSSturmbannführer und seine Leute formell zur Militärverwaltung, ihre Instruktionen indes bezogen sie aus Berlin. Ihr ursprünglicher Auftrag lautete, ideologische Feinde des Reichs zu überwachen; dabei waren sie jedoch an Weisungen des Mili-

$110 \mathrm{Vgl}$. Aktenvermerke Best vom 11. und 18. 9. 1940; CDJC, XXIV-6 und 8.

111 Verordnungsblatt für die besetzten französischen Gebiete, Nr. 9 vom 30. 9. 1940 (Rückkehrverbot, Meldepflicht, Aufbau eines Judenregisters, Kennzeichnungszwang jüdischer Geschäfte); Nr. 12 vom 20. 10. 1940 (Meldepflicht für alle jüdischen Wirtschaftsunternehmen in Vorbereitung ihrer, Arisierung'). Am 1. Oktober wurde Abetz erneut aktiv: Er regte in Berlin ein Kollektivausbürgerungsverfahren für im besetzten Frankreich lebende reichsdeutsche Juden an; CDJC, LXXI-39.

112 „Eidliche Erklärung“ vom 30. 5. 1947, pag. 4. "Aktivität der Botschaft in Judenfragen“, pag. 1. Abetz-Prozeß, 15.7. 1949, pag. 73 ff.

113 Herbert, Best, S. 264. Aufzeichnung Luthers vom 21. 8. 1942 zur Judenpolitik; ADAP, E III, Nr. 209, S. 354.

114 Heydrich an Luther, 20. 9. 1940; PA/AA, R 100869. Luther hatte am 23. August und am 10. September auf eine „grundsätzliche Stellungnahme“ des Reichsführer-SS gedrängt; ebenda.

115 Aufzeichnung Dannecker (Sipo/SD Paris) vom 21. 1. 1941; abgedruckt Klarsfeld, VichyAuschwitz, S. 363. 
tärbefehlshabers gebunden und ohne eigene Exekutivgewalt ${ }^{116}$. Daß ihr Einfluß dennoch stetig wuchs, lag an ergiebigen Kontakten zur französischen Polizei und an der zentralen Rolle, die sie vom Herbst 1940 an bei der Judenverfolgung spielten.

Wie überall im nationalsozialistischen Herrschaftsraum lösten auch in Frankreich verschiedene Phasen judenfeindlicher Politik einander ab. Zuerst wurden die Opfer entrechtet und enteignet, später verhaftet und der Vernichtung preisgegeben. Die ersten Sanktionen hatte Otto Abetz auf den Weg gebracht. Als nun Sipo und SD die Initiative an sich rissen, allen voran Theo Dannecker, ein Vertrauter Eichmanns, der schon in Wien, Prag und Berlin als kaltblütiger Organisator jüdischer Zwangsemigration hervorgetreten war ${ }^{117}$, konnten sie auf kollegiale Hilfe und diplomatischen Flankenschutz der Botschaft zählen. Gemeinsam trieben Vertreter beider Dienststellen die „Säuberung“" Frankreichs vom Judentum voran, wobei sie der grundsätzlichen Rückendeckung ihrer Berliner Vorgesetzten gewiß sein durften. Schon am 24. Juni 1940 hatte Heydrich dem Reichsaußenminister mitgeteilt, angesichts von mehr als drei Millionen Juden unter deutscher Hoheitsgewalt greife die seitherige Auswanderungspraxis zu kurz: „Eine territoriale Endlösung wird daher notwendig." 118 Am 4. August notierte der Judenreferent des AA, Legationsrat Franz Rademacher, Ribbentrop habe einer Abschiebung der Juden zugestimmt: „Es soll im engen Einvernehmen mit den Dienststellen des Reichsführer-SS vorgegangen werden. " 119

Der spezifische Beitrag der Pariser Botschaft spiegelt die komplizierten staatsrechtlichen und besatzungspolitischen Verhältnisse nach dem deutsch-französischen Waffenstillstand vom Juni 1940 wider. „Kein anderes Land in Europa wies allein in der territorialen Durchführung antijüdischer Maßnahmen ähnliche Verwicklungen auf wie Frankreich", urteilt der Holocaust-Chronist Raul Hilberg120. Und kaum sonst irgendwo war die deutsche Abhängigkeit von der heimischen Administration größer - auch dies eine Folge der Teilsouveränität Vichys und des Personalmangels bei den Besatzern, die auf Methoden der "Aufsichtsverwaltung" zurückgreifen mußten und auch zur, Endlösung tatkräftige Unterstützung französischer Behörden brauchten ${ }^{121}$. Deren Beteiligung am Vernichtungswerk war anderseits ausdrücklich erwünscht, „um die Reaktion des französischen Volkes gegen alles, was von den Deutschen kommt, auf diesem Gebiete auszuschalten“,

116 Zur institutionellen Stellung und den Anfängen von Sipo und SD in Paris Kasten, „Gute Franzosen“, S. 22 ff.; Burrin, La France, S. 96f.; Umbreit, Militärbefehlshaber, S. $107 \mathrm{ff}$.

117 Zum Werdegang Danneckers Safrian, Eichmann-Männer, S. 23 ff.; Klarsfeld, VichyAuschwitz, S. $36 \mathrm{ff}$.

118 Zit. bei Döscher, Auswärtiges Amt, S. 217. „Territoriale Endlösung“ meinte zum damaligen Zeitpunkt die Vertreibung der Juden aus Europa und ihre Ansiedlung etwa auf $\mathrm{Ma}$ dagaskar.

119 Zit. ebenda, S. 216. Diese Entwicklung, die sich mit Hitlers Aussagen am 3. August deckt, liefert den größeren politischen Rahmen für Abetz' Forderungen nach „antisemitischen Sofortmaßnahmen“. Die enge Kooperation von AA und RSHA unterstreicht Luther in seinem schon erwähnten Memorandum vom August 1942; ADAP, E III, S. 355.

120 Hilberg, Vernichtung, 2, S. 648.

121 Ebenda, S. 642; Kasten, „Gute Franzosen“, S. 213 ff.; Umbreit, Militärbefehlshaber, S. 27 und passim. 
wie ein hochrangiger SD-Funktionär Ende Januar 1941 Best und seinen Mitarbeitern darlegte ${ }^{122}$. Die Exekutivgewalt des Militärbefehlshabers wiederum wurde benötigt, um geplante antijüdische Maßnahmen in Verordnungen der Besatzungsmacht zu kleiden.

In diesem Geflecht wechselseitiger Abhängigkeiten sahen die Diplomaten ihren Part offenkundig darin, Sipo und SD - eigentlich Organe des Reichsinnern - die Tätigkeit jenseits des Rheins zu erleichtern. Die jeweiligen Stadien der ,Endlösung' wurden auf eine Weise gefördert, die Errungenschaften der Kollaboration bewahren solite und darauf zielte, Franzosen einzuspannen und antisemitische Strömungen im Land zu stärken. „In der gesamten Judenfrage, in der der SD an sich federführend ist, wurde der politische Sektor ausschließlich von der Botschaft betreut", notierte Abetz' Sachbearbeiter Dr. Carltheo Zeitschel. Sowohl Knochens Leute als auch die Militärverwaltung erhielten „entsprechende Weisungen"123. Best bezeugte einen laufenden Meinungsaustausch mit Abetz, „der - um Arbeitszeit zu sparen - wöchentlich bei einem Frühstück stattfand, zu dem ich in die Botschaft eingeladen wurde"124. Mitte 1941 vereinbarte Dannecker mit Vertretern von „Majestic“ und Rue de Lille regelmäßige Konferenzen, die sogenannten "Dienstagsrunden“, auf daß "nunmehr jedes Gegen- und Nebeneinander in der jüdischen Frage im besetzten Gebiet unmöglich gemacht ist" ${ }^{125}$. Im Ergebnis arbeiteten die häufig zerstrittenen deutschen Dienststellen diesmal mit verteilten Rollen, zum Teil auch mit unterschiedlichen Kompetenzansprüchen, letztlich aber doch Hand in Hand ${ }^{126}$. Beispielhaft dafür ist die Entstehungsgeschichte des französischen Generalkommissariats für Judenfragen im ersten Quartal 1941.

Mit dem Jahreswechsel begann eine neue Phase judenfeindlicher Politik in Frankreich. Sipo und SD empfahlen, schleunigst ein "Zentrales Judenamt" unter französischer Leitung und deutscher Aufsicht zu gründen, das der geplanten „Gesamtabschiebung der Juden" durch Segregation und Überwachung, Arisierung und Propaganda systematisch vorarbeiten sollte. Zwar war immer noch unklar, wohin mit ihnen, doch wollte man für den Tag X gerüstet sein. Empörend fand Dannecker in diesem Zusammenhang, daß die Landesbehörden einer "Generalreinigung" vielfach blankes Unverständnis entgegenbrächten; aus strategischen wie personellen Gründen war ihr Mitwirken indes zwingend erforderlich ${ }^{127}$. Knochen faßte in einem Schreiben an die Militärverwaltung gleich noch ein weiteres „Teilstück“ auf dem Weg zur ,Endlösung“ ins Auge: Konzentrationslager für nicht-französische Juden auch im besetzten Frankreich. Davon versprach er sich

122 Aufzeichnung Mahnke, 3. 2. 1941; abgedruckt Klarsfeld, Vichy-Auschwitz, S. 364.

123 Jahresbilanz Zeitschel vom 13. 6. 1941; PA/AA, Botschaft Paris 1321.

124 Erinnerungen aus dem besetzten Frankreich, Manuskript von 1951 aus dem Nachl. Best; BDIC, Dok.-Sammlung BA.

125 "Judenfrage in Frankreich und ihre Behandlung", pag. 26f.; IMT, RF-1207. Aktenvermerk Storz (Militärverwaltung), 10. 6. 1941; AN, AJ 40/548. Aufzeichnung Dannecker vom 22. 2. 1942, abgedruckt Klarsfeld, Vichy-Auschwitz, S. $371 \mathrm{ff}$.

126 Resümierend Klarsfeld, Vichy-Auschwitz, S. 22; ders., Endlösung, S. 10f.; Billig, Endlösung, S. 134 ff.; Herbert, Best, S. 306 ff.; Fox, "German Bureaucrat“, S. $186 \mathrm{f}$.

127 Aufzeichnung Dannecker vom 21. 1. 1941; Protokoll einer Besprechung Dannecker/ Lischka/Best am 30. Januar; abgedruckt Klarsfeld, Vichy-Auschwitz, S. 361 ff. 
neue Impulse und mehr Akzeptanz bei der Bevölkerung, deren Judengegnerschaft sich „hauptsächlich gegen die fremden Elemente richtet“128.

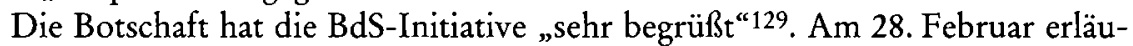
terte Dannecker seine Pläne Abetz, Achenbach und Zeitschel, wobei er Judenamt und Konzentrationslager ohne Umschweife verknüpfte ${ }^{130}$. Er verwies auf "gewissenhafte Zählungen“ des SD und eine „vorbildliche“ Kartei, in welcher Namen, Staatsangehörigkeit, Beruf und Adressen von fast 150000 Juden im Großraum Paris - gut zwei Fünftel davon Ausländer oder staatenlos - gespeichert waren ${ }^{131}$. Sein Begehr: Vollmachten und logistische Hilfe der Militärverwaltung für Razzien und Festnahmen. Begründen ließen sie sich mit Sicherheitsrisiken der Besatzungsarmee durch jüdische Hetzpropaganda und dem Umstand, daß im unbesetzten Frankreich aufgrund des Vichy-Gesetzes vom 4. Oktober 1940 bereits 40000 Juden inhaftiert worden seien. Noch am selben Tag schickte Dannecker Zeitschel eine Abschrift des Knochen-Briefs vom 28. Januar ${ }^{132}$ - ein Fingerzeig, wie wichtig ihm das KZ-Thema war, und vermutlich auch ein Hinweis darauf, daß sich die Militärverwaltung sträubte, anderen Diensten Exekutivgewalt zu übertragen, wiewohl ein Werner Best radikale antijüdische Kampagnen im Grundsatz guthieß ${ }^{133}$. Die Botschaft ergriff in dieser Situation Partei für die weitreichenden Forderungen des BdS. Abetz und Dannecker kamen überein, weitere Gespräche zu führen, „mit den in Frage kommenden Franzosen [...], vor allem aber mit dem Militärbefehlshaber wegen der notwendigen Vollmachten".

Anderntags unterbreitete der Botschafter seinem zuständigen Referenten Vorschläge, wer als Mitarbeiter für ein Zentrales Judenamt tauge ${ }^{134}$ : Francisten-Chef Marcel Bucard; Louis Darquier de Pellepoix, Präsident der Sammlungsbewegung „Rassemblement anti-juif de France“; Jean Boissel, ein seit Jahren für Hitler eingenommener Rassist, 1939 der Spionage für Deutschland beschuldigt, nun an der Spitze des „Front franc" und der Zeitung Le Réveil du peuple; Pierre Clémenti, Vorsitzender des „Parti français nationale collectiviste“. Alle vier waren militante Antisemiten und Vertreter jener rechtsextremen Pariser Splittergruppen, denen Abetz nach dem für ihn so enttäuschenden Sturz Lavals am 13. Dezember 1940 Entfaltungsmöglichkeiten gewährte, um Vichy unter Druck zu setzen und dem Kollaborationsgedanken einen populären Anstrich zu geben ${ }^{135}$. Darüber hinaus

128 Knochen an den Chef der Militärverwaltung Frankreich/Verwaltungsstab, 28. Januar; ebenda, S. $363 \mathrm{f}$.

129 Schreiben an den BdS, 14. Februar, mit Paraphe Abetz'; ebenda, S. 365.

130 Aufzeichnung vom 28. Februar, „Betr.: Zentrales Judenamt in Paris“; ebenda, S. 365 f.

131 Diese Angaben nach Klarsfeld, ebenda, S. 26. Dannecker nannte in der Konferenz am 28. Februar überhöhte Zahlen, vor allem hinsichtlich des Ausländer-Anteils. Die Kartei, verwaltet in der Pariser Polizei-Präfektur, geht zurück auf die Verordnung des Militärbefehlshabers vom 27. 9. 1940 (Meldepflicht und Aufbau eines Judenregisters).

132 Ebenda, S. 366.

133 Mit diesem Tenor Herbert, Best, S. 308f. In seinem Memorandum vom Juli 1941 notierte Dannecker zu den Gesprächen Ende Januar, die Militärverwaltung habe sich an einem Judenamt „desinteressiert“ gezeigt; IMT, RF-1207.

134 Abetz, „Notiz für Herrn Zeitschel“, 1. 3. 1941; CDJC, V-65.

135 Vgl. Protokoll einer Besprechung in der Botschaft am 7.1. 1941; AN, AJ 40/551, Dossier 3. Gerade in der gegenwärtigen politischen Lage, so Abetz, sei „die Bearbeitung der 
nannte Abetz die Autoren Céline, Jean de La Hire, Comte Armand de Puységur, vor dem Krieg in der "Ligue antimaçonnique" aktiv, und Clément Serpeille de Gobineau, Kolumnist in Châteaubriants Magazin La Gerbe, einst erklärter Widersacher des Ribbentrop-Referenten, nun offenbar willkommen als Helfershelfer im Feldzug gegen die Juden. Als „Persönlichkeiten für eine sachlich wirksame Arbeit" empfahl der Botschafter schließlich noch den von ihm protegierten Chefredakteur der Wochenzeitung L'Illustration, Jacques de Lesdain, und den Völkerkundler und Rassentheoretiker Professor Georges Montandon, der im Dezember 1941 zum Generalkommissariat für Judenfragen stieß136. Zeitschel leitete die Vorschläge zusammen mit dem Knochen-Brief an seinen direkten Vorgesetzten Achenbach weiter und drängte - ganz im Sinne des BdS - auf energisches Handeln in Sachen Konzentrationslager. Es sei Zeit für ein "vom Botschafter selbst gezeichnetes" Schreiben an die Militärverwaltung, das „vielleicht etwas energischer gehalten sein kann als der Brief vom SD, mit der Weisung, möglichst umgehend dem Wunsche des SD zu entsprechen". Das weitere Vorgehen in der Judenfrage müsse unverzüglich abgestimmt werden ${ }^{137}$.

Die gemeinsame Linie von BdS und Botschaft zeigte Wirkung: Am 27. März 1941 informierte Best die Kommandanten der Militärbezirke, daß die französische Regierung gewillt sei, ausländische Juden in der besetzten Zone zu internieren; die Präfekten würden angewiesen, nach geeigneten Orten zu suchen ${ }^{138}$. Stülpnagel billigte demnach Massenverhaftungen, die im Zuge der „Aufsichtsverwaltung" von französischen Polizeikräften zu vollstrecken waren, und wahrte zugleich seine Machtbefugnisse. Gleichwohl ist nicht zu übersehen, daß Knochen und Dannecker ebenso wie Abetz und Zeitschel die Entwicklung mit ihrer Beharrlichkeit beeinflußt haben. Entscheidende Weichen für die sich anbahnende Vernichtung der europäischen Juden waren nun auch in Frankreich gestellt. Jede künftige Verschärfung des Kurses - Großrazzien, mörderische Haftbedingungen, Vergeltungsmaßnahmen nach Attentaten, Einführung der israelitischen Zwangsvereinigung UGIF und des Judensterns, schließlich die Deportationen nach dem Osten, wobei teils willkürlich, teils nach Verhandlungen mit der Vichy-Regierung

uns zugewandten aktivistischen französischen Kreise von höchster Wichtigkeit. Es kommt jetzt darauf an, der gegnerischen Behauptung, die Collaboration sei 100prozentig unpopulär, mit allen Mitteln entgegenzutreten und den Nachweis für unsere These zu erbringen, daß die breiten Massen trotz der bestehenden materiellen Schwierigkeiten und trotz Schimpfen für eine Zusammenarbeit mit Deutschland sind." Aus deutscher Sicht relevant war im übrigen einzig, daß die kollaborationistischen Groupements einheitlich für eine „neue europäische Ordnung " unter nationalsozialistischen Prämissen trommelten; innenpolitisch mochten sie im Interesse der Besatzer getrost konkurrieren. $\mathrm{Zu}$ diesem Themenkomplex Burrin, Le collaborationisme, in: Azéma/Bédarida (Hrsg.), La France des années noires, 1, S. 363 ff.; ders., La France, Kap. XXIV; Paxton, Vichy France, S. $249 \mathrm{ff}$.; Gordon, Collaborationism; Ory, Les collaborateurs.

136 Zu Montandon Billig, Commissariat Général, I, S. 138 ff.; Ory, S. 154f.; Cohen, Pérsecutions, S. $346 \mathrm{ff}$.

137 Aufzeichnung Zeitschel, 1. 3. 1941, „Gesandtschaftsrat Achenbach zur weiteren Veranlassung vorgelegt"; CDJC, V-61.

138 Schreiben vom 27.3. 1941; CDJC, LXXVII-4. Vgl. Schleier an Auswärtiges Amt, 24. März; ADAP, D XII.1, Nr. 198. 
auch tausende französischer Juden in den Tod geschickt wurden - fand die ausdrückliche, häufig auf taktische Erfordernisse ausgerichtete, nicht selten gleichgültig anmutende Zustimmung der Botschaft. Die Verantwortlichen in der Rue de Lille machten sich gemein mit all jenen Schreibtischtätern, die den Holocaust auf diplomatischem Terrain vorbereiten und abschirmen halfen ${ }^{139}$.

Exemplarisch für Abetz' Verstrickung ist ein Telegramm vom 2. Juli 1942: Gegen den Abtransport von 40000 Juden zum „Arbeitseinsatz“ in Auschwitz, heißt es da, „bestehen seitens der Botschaft grundsätzlich keine Bedenken“. Es folgt der Hinweis, daß die Botschaft bei antijüdischen Schritten stets den Standpunkt vertreten habe, „daß diese in einer Form durchgeführt werden sollen, die das in der letzten Zeit gewachsene antisemitische Gefühl ständig weiter erhöht [...]. Es wird deshalb psychologisch in den breiten Massen des französischen Volkes wirksam sein, wenn die Evakuierungsmaßnahmen zunächst einmal [...] fremdländische Juden erfassen und daß auf die französischen Juden zunächst nur in dem Umfang zurückgegriffen wird, in dem die Juden ausländischer Staatsangehörigkeit nicht für das angegebene Kontingent ausreichen." Spätere Beteuerungen, man habe „durch eine gewisse Aktivität in der Wirkung viel tiefgreifendere Maßnahmen“ aufhalten wollen ${ }^{140}$, in diesem Fall eine kleinere Personengruppe zugunsten einer größeren geopfert, werden durch Abetz' Schlußsatz entwertet: „Mit einem solchen Vorgehen würde keineswegs dem französischen Juden eine privilegierte Stellung eingeräumt, da er im Zuge der Freimachung der europäischen Länder vom Judentum auf alle Fälle ebenfalls verschwinden muß, was darin schon zum Ausdruck kommt, daß [...] in dem angegebenen Kontingent eine gewisse Zahl von französischen Juden erfaßt wird. "141

Nicht weniger berechnend klingen seine Ratschläge für eine Sprachregelung, als Hitler nach einer Attentatsserie gegen Wehrmachtsoldaten im Dezember 1941 eine Geldbuße von 1 Milliarde Francs gegen die Juden im besetzten Frankreich verhängt und die Erschießung von 100 Geiseln sowie die Deportation einer „groBen Zahl verbrecherischer jüdisch-bolschewistischer Elemente" nach dem Osten befiehlt ${ }^{142}$. „Die Attentate“, so der Botschafter, „sollen [...] den Eindruck erwekken, daß sich das französische Volk gegen die deutsche Besatzungsmacht und gegen den Gedanken einer Zusammenarbeit mit Deutschland auflehnt [...] Daraus ergibt sich, daß unser politisches Interesse in der gegenteiligen Behauptung liegt. Selbst dort, wo eine französische Täterschaft offen nachgewiesen werden kann, empfiehlt es sich nicht, diese Feststellung groß herauszustellen, sondern

139 Eine umfassende Bibliographie zur Judenverfolgung in Frankreich während des Zweiten Weltkriegs bei Klarsfeld, Vichy-Auschwitz, S. $585 \mathrm{ff}$.

140 Aufzeichnung Schleiers als Anlage zu einem Brief an Abetz vom 19. 7. 1957; PA/AA, Nachl. Schleier/I.6.

141 Abetz an Auswärtiges Amt, 2. 7. 1942; ADAP, E III, Nr. 58. Dieselbe Strategie schon in der Morgenbesprechung der Botschaft am 1. 4. 1941: Es seien „zunächst nur scharfe Judengesetze gegen die ausländischen Juden zu erlassen, um erst später und langsam auch gegen die französischen Juden vorzugehen“. Aufzeichnung Schuchardt (Verbindungsoffizier MBH/Botschaft); AN, AJ 40/1202.

142 Die Bekanntmachung des Militärbefehlshabers Frankreich vom 14. 12. 1941 ist abgedruckt in ADAP, E I, Nr. 16. 
[...] die These zu vertreten, daß es sich ausschließlich um Juden und gekaufte Agenten angelsächsischer und russischer Geheimdienste handelte. "Von ebensolchen solle auch bei Exekutionen die Rede sein. Darüber hinaus würden "schärfste Geldbußen gegen die Juden und die plutokratische Oberschicht ihre propagandistische Wirkung nicht verfehlen, insbesondere wenn ein Teil dieser Gelder sozialen Zwecken in Frankreich zugeführt würde" ${ }^{143}$. Wer Angehörige einer Bevölkerungsgruppe derart zu Sündenböcken stempelt, sie wie Freiwild behandelt und als politische Manövriermasse mißbraucht, kann hernach schwerlich glaubhaft machen, er habe sie in irgendeiner Weise schonen wollen. Abetz' Richter pflichteten ohne Abstriche der Anklage bei, die von Verfolgung, Freiheitsberaubung und nackter Gewalt sprach und es als erwiesen ansah, daß er in sämtliche Phasen der ,Endlösung in Frankreich eingeschaltet war: „Il a tout connu, tout su, tout approuvé. Il n'a pas élevé de protestations; au contraire, il a fait pression sur le Gouvernement français." 144

Solcher Druck manifestierte sich auch bei der Einrichtung des Generalkommissariats für Judenfragen. Während eines Abendessens in der Botschaft am 5. März 1941 hatte der stellvertretende Ministerpräsident der Vichy-Regierung, Admiral François Darlan, zwar grundsätzliches Entgegenkommen signalisiert, zugleich aber auf Pétains Weigerung verwiesen, alteingesessene und im Krieg ausgezeichnete Juden auf eine Stufe mit eingewanderten und nach Frankreich geflüchteten zu stellen. Aus strategischen Gründen pochte Abetz trotzdem unvermindert auf französische Regie: „Das zentrale Judenamt erhält dadurch eine gesetzlich gültige Grundlage, und es kann durch deutschen Einfluß im besetzten Gebiet derart aktiviert werden, daß das unbesetzte Gebiet gezwungen ist, sich den getroffenen Maßnahmen anzuschließen. " ${ }^{145}$ Als Dannecker 14 Tage später argwöhnte, Vichy trachte die Entscheidung zu verzögern, machte er seinem Ärger bei Achenbachs Mitarbeiter v. Nostitz-Wallwitz Luft: Die Franzosen müßten endlich Farbe bekennen. Nostitz erwiderte, es sei ja auch „der Weg über Herrn de Brinon denkbar"; Dannecker werde „morgen noch von uns hören“"146. Neun Tage später ernannte die französische Regierung Xavier Vallat zum Generalkommissar für Judenfragen ${ }^{147}$. Es ist davon auszugehen, daß die deutschen Diplomaten zwischenzeitlich noch einmal energisch intervenierten. Dannecker jedenfalls notierte be-

143 Auszugsweise Abschrift eines Berichts der Botschaft Paris vom 7. 12. 1941, gez. Abetz; vgl. ders., Aufzeichnung einer "telefonischen Mitteilung an Herrn Strack" (AA), 12. Dezember. Die Beispiele ließen sich fortsetzen. Daß seine Argumentation verfing, belegt eine Notiz Ritters (Berlin) für Ribbentrop vom 13. Dezember: Der ,Führer' habe die vorgeschlagenen Sanktionen angeordnet mit der Auflage, ,die notwendigen Veröffentlichungen und propagandistischen Maßnahmen sind im Einvernehmen mit Abetz vorzunehmen“. PA/AA, R 27779.

144 Plädoyer des Anklägers, Capitaine Flicoteaux; Abetz-Prozeß, 21. 7. 1949, pag. 39; AN, 334 AP 49. Der Schuldspruch stützte sich unter anderem auf die einschlägigen Artikel 341,342 und 344 des Militärstrafgesetzbuches.

145 Abetz an Auswärtiges Amt, 6. 3. 1941; ADAP, D XII.1, Nr. 127.

146 Aufzeichnung Nostitz, 20.3. 1941; CDJC, V-83, abgedruckt Klarsfeld (Hrsg.), Endlösung, S. 19.

147 "Loi du 29 mars 1941 créant un commissariat général aux questions juives“; Journal Officiel, 31. 3. 1941, S. 1386. 
friedigt, „stetes Drängen“ von SD und Botschaft habe über die „alte Verschleppungstaktik" des französischen Ministerrats obsiegt ${ }^{148}$.

Xavier Vallat, schwerkriegsbeschädigter nationalistischer Kammerabgeordneter der ,Dritten Republik‘, 1940 Schöpfer der pétaintreuen Einheitsorganisation "Légion française des combattants“, galt als entschiedener Antisemit, keineswegs aber als Freund der Deutschen. Ohne den primitivsten Blut- und Boden-Theorien anzuhängen, war er doch überzeugt, daß Juden immer ein parasitärer Fremdkörper im Staat bleiben würden und ihr Einfluß bekämpft werden mußte; dazu gehörte, die Flut der Flüchtlinge und Neuankömmlinge aus den letzten Jahren wieder abzuschieben ${ }^{149}$. Als Generalkommissar sollte er nach deutscher Vorstellung die Ausführung der bereits erlassenen Judengesetze überwachen und - in Abstimmung mit den Besatzern - weitere ausarbeiten. Bei seinem Antrittsbesuch in der Rue de Lille am 3. April 1941 hinterließ er einen günstigen Eindruck ${ }^{150}$. In seinem Rapport an das Auswärtige Amt betonte Abetz allerdings, daß Vallat in Etappen vorgehen müsse, um nicht sofort in offenen Widerspruch zu Pétain zu geraten. Dessen Tendenz, französische Juden zu schonen, zog der Botschafter mit der ihm eigenen Beweglichkeit ins Kalkül. Er entwarf einen Stufenplan. Ins Visier sollten zunächst vor allem ausländische und erst vor kurzem naturalisierte Juden rücken. Parallel dazu sollte Vallat ein Gesetz vorbereiten, das ihn mittelfristig ermächtigen würde, „alteingesessene“ Juden zu „ausländischen" zu erklären, wenn sie gegen „nationale und soziale Interessen der französischen Nation" verstießen. Auf solche Weise könnte auch diese Gruppierung „nach und nach restlos zum Verlassen Frankreichs gebracht werden" 151 .

Vallats Tätigkeit in den folgenden Monaten zielte vor allem darauf, die jüdische Bevölkerung aus freien Berufen, Handel und Gewerbe hinauszudrängen, die vollständige Kontrolle über ihr Vermögen zu erlangen und sie auch in der unbesetzten Zone zu registrieren; unter seiner Federführung wurden einschlägige Gesetze auch für die französischen Kolonien erlassen ${ }^{152}$. In Vichy eckte er mit seinem Aktionismus zusehends an. Im Januar 1942 befahl Darlan, die Methoden des Kommissars zu überprüfen: „J'ai l'impression que M. Vallat va un peu fort et qu'il ne suit pas les directives qui sont de ne pas ,embêter les vieux juifs français" 153 . Die Deutschen dagegen hielten den beschriebenen Kurs von Anfang an für zu lax. Schon während Vallats Antrittsbesuch beim Militärbefehlshaber hatte Best erfahren müssen, daß der Judenkommissar gewillt war, auf die Stimmung seiner Landsleute, die „sentimental und von einem ausgeprägten Gerechtigkeitsgefühl beseelt“ seien, Rücksicht zu nehmen. Auch bat er zu bedenken, daß „seriöser Antisemitismus" in Frankreich bislang fast unbekannt sei, und warnte vor "unerfreulichen Konjunkturrittern" wie den Autoren der Zeitschrift Au Pilori. Bests Forderungen

148 Dannecker, "Judenfrage in Frankreich“, 1. 7. 1941; IMT, RF-1207.

149 Vgl. Marrus/Paxton, Vichy France, S. 87 ff.; Hilberg, Vernichtung, 2, S. $658 \mathrm{ff}$.

150 In der Wochenkonferenz der Botschaft war Abetz voller Zuversicht: „Vallat gilt als energische Persönlichkeit." Aufzeichnung Schuchardt, 3. 4. 1941; AN, AJ 40/1202.

151 Abetz an Auswärtiges Amt, 3. 4. 1941; ADAP, D XII.1, Nr. 254.

152 Marrus/Paxton, Vichy France, S. $98 \mathrm{ff}$.

153 Darlan an Moysset, 15. 1. 1942, abgedruckt Bégarie/Huan (Hrsg.), Lettres et notes de l'Amiral Darlan, S. 468. 
- Ausweisung fremdländischer und über kurz oder lang auch einheimischer Juden, Internierung von 3000 bis $\mathbf{5 0 0 0}$ politisch mißliebigen oder kriminellen Israeliten jedweder Staatsangehörigkeit - konterte er mit dem Hinweis, all dies sei Sache der Verwaltungs- und Polizeibehörden. Zudem wisse er kaum noch Länder, die bereit seien, Juden aufzunehmen ${ }^{154}$. Enttäuscht meinte Best, der „unangenehme Teil“" werde letztlich wohl doch an der Militärverwaltung hängenbleiben 155 .

Wenig später stand Vallat im Kreuzfeuer der deutschen Kritik. Er habe „offen zu verstehen gegeben, daß er unnötige Härten gegen die Juden vermeiden möchte “, empörte sich Dannecker ${ }^{156}$. Im Februar 1942 eskalierte der Zwist. Die verschiedensten Dienststellen führten Klage gegen Vallat, der allgemein als ,Judenschutzkommissar" angesehen werde, beschwerte sich Best bei Botschafter Brinon und verlangte personelle Konsequenzen. Brinon erwiderte, Abetz habe tags zuvor „in demselben Sinn“ mit ihm gesprochen; er wollte sich „persönlich beim Marschall" um die Angelegenheit kümmern und meldete am 1. März, Vallats Ablösung sei beschlossene Sache ${ }^{157}$. Zum Nachfolger bestimmte der soeben an die Regierungsspitze zurückgekehrte Laval im Mai den Pariser Stadtrat Louis Darquier de Pellepoix. Der Arztsohn aus Cahors, ein berüchtigter Aufwiegler, vorbestraft wegen Anstiftung zum Rassenhaß, publizierte vor Kriegsausbruch mit Finanzspritzen aus nationalsozialistischen Quellen die antisemitische Wochenzeitung La France enchainée. Die Botschaft hat seine Wahl lebhaft befürwortet: „Sollte diese Ernennung durchkommen, dann darf angenommen werden, daß in der nächsten Zeit sehr klare und unmißverständliche Maßnahmen gegen die Juden ergriffen werden", heißt es in einem Schreiben an den Militärbefehlshaber. Auch sei eine verstärkte Propaganda zu erwarten, die die geplante Einführung des Judensterns „ohne unerwünschte Rückwirkungen und Nebenerscheinungen“" ermöglichen werde ${ }^{158}$.

Darquier war bemüht, die Erwartungen zu erfüllen ${ }^{159}$. Als er sein Amt antrat, hatte die Judenverfolgung in Frankreich das Stadium der physischen Vernichtung erreicht. Die Botschaft favorisierte in dieser Phase einen Mann, der Deportationen einen Akt öffentlicher Hygiene nannte; ein Jahr zuvor hatte sie noch die Ankunft Vallats begrüßt, der Entrechtung und Enteignung der jüdischen Bevölkerung auf juristischem Weg vorantrieb. Beide Vorgänge werfen grelles Licht auf die Bereitschaft der Diplomaten, die ,Endlösung‘ zu unterstützen und sich dabei größtmöglicher französischer Schützenhilfe zu bedienen. Mit der wortreich beteuerten

154 „Besprechungsplan“ Bests für den Militärbefehlshaber, 4. 4. 1941, abgedruckt Klarsfeld, Vichy-Auschwitz, S. $366 \mathrm{f}$. Protokoll der Unterredung mit Vallat vom 5. April; CDJC, XXIV-15.

155 Aktenvermerk Zeitschel, 5. April; CDJC, V-81. Vgl. Herbert, Best, S. $307 \mathrm{f}$. Sehr pointiert die Interpretation von Billig, Endlösung, S. $141 \mathrm{ff}$.

156 "Judenfrage in Frankreich“; IMT, RF-1207.

157 Aufzeichnung Beumelburg über Gespräch Best-Brinon am 19. 2. 1942, Aktenvermerk Best vom 2. März; AN, AJ 40/548.

158 Zit. in einem Schreiben Bests an den BdS, 31. 3. 1942; CDJC, XLIXa-4.

159 Marrus/Paxton, Vichy France, S. 283 ff.; Kaspi, Les Juifs, S. 73 ff., 219, 237, 252; Klarsfeld, Vichy-Auschwitz, S. $52 \mathrm{f}$. 
Absicht, letztere habe ein "Gegengewicht" zur "deutschen Einmischung" im Nachbarland schaffen sollen ${ }^{160}$, ist ihr Verhalten schwerlich in Einklang zu bringen.

Auch sein propagandistisches Potential entfaltete Abetz in der Judenfrage. Erneut suchte er einen selbstdefinierten „Leitsatz“ ideologischer Wühlarbeit zu beachten: Franzosen, nicht Deutsche sollten „nach außen hin im stärksten Maße [...] als Träger der Propaganda erscheinen“, um die Wirkung im besetzten Land zu steigern ${ }^{161}$. Deutlich wird diese Strategie nicht nur bei der Presselenkung und der Unterstützung kollaborationistischer Parteien, sondern ebenso am Beispiel des „Institut d'étude des questions juives“ (IEQJ). Auf Betreiben Danneckers im Frühjahr 1941 gegründet, führte es mehrere antisemitische Vereinigungen zusammen, die sich radikaler gebärdeten als der staatliche Judenkommissar Vallat. Zentrale Gestalt bis Mitte 1942 war Capitaine Paul Sézille, vor dem Krieg Darquiers rechte Hand im Rassemblement anti-juif. Er verstand sich als Speerspitze eines Antisemitismus à l'allemande und Schrittmacher einer verschärften Gesetzgebung Vichys. Das ,Institut' und ein nach deutschen Angaben etwa 3000 Mitglieder zählender Freundeskreis eröffneten ein propagandistisches Trommelfeuer in Wort und Schrift, pseudo-wissenschaftlich verbrämt. Spezialkommandos spürten Juden auf und denunzierten sie bei der Gestapo ${ }^{162}$.

In der Botschaft schrieb man Sézilles Organisation die Aufgabe zu, eine breite Öffentlichkeit aufzuklären, „was Juden sind und in welch verderblicher Art sie in Frankreich und in der ganzen Welt bisher gearbeitet haben "163. Dabei wußte man sich einmal mehr „im engsten Einvernehmen "164 mit dem SD. Dannecker erhielt zur Finanzierung des Instituts "größere Geldbeträge“ aus der Rue de Lille - „aus freien Stücken ", wie er lobend erwähnte ${ }^{165}$. Komplett unter ihre Fittiche nahm die Botschaft die ab März 1942 vom Institut herausgegebene Zeitschrift La Question juive en France et dans le monde, die französischen "Wissenschaftlern" ein Forum

160 Abetz, „Aktivität in Judenfragen“; PA/AA, Nachl. Schleier/I.

161 Abetz an Ribbentrop, 3. 12. 1940; PA/AA, R 29588. Um die Jahreswende 1942/43 sah der Botschafter den seitherigen Erfolg deutscher Propaganda in Frankreich dadurch geschmälert, „daß sie zu deutlich als vom Reich her inspiriert in Erscheinung getreten ist“. Abetz (Berlin) an Botschafter Ritter, „Vorschläge zur künftigen Handhabung der Propaganda und Zensur im altbesetzten und neubesetzten Frankreich“, 4.1. 1943; PA/AA, R 102966.

162 Einzelheiten bei Billig, Commissariat Général, II, S. $271 \mathrm{ff}$.; Cohen, Persécutions, S. 149 ff.; Marrus/Paxton, Vichy France, S. 211 f.; Dossier "L'Institut d'étude des questions juives“, unsig., 16. 12. 1946; CDJC, XCVI-80. Informationsblatt Sézilles von 1942; Sézille an Laval, 17. 12. 1942; PA/AA, Botschaft Paris 1190.

163 Jahresbilanz Zeitschel, 13. 6. 1941; PA/AA, Botschaft Paris 1321.

164 Klassen (Informationsabteilung) an den Kommandanten von Groß-Paris, 1. 2. 1943; PA/ AA, Botschaft Paris 1175.

165 "Judenfrage in Frankreich“, pag. 55; IMT, RF-1207. Zeitschel teilte am 5. 9. 1941 mit, "daß ich für das Judeninstitut vorsichtshalber 200000 Francs beantragt habe und daß dieselben [...] genehmigt worden sind“; CDJC, V-73. Die Informationsabteilung errechnete Juni 1942 einen monatlichen Zuschußbedarf von 40000 Francs; 600000 Francs seien dem SD bislang für das IEQJ überlassen worden. Legationsrat Buscher, Aufzeichnung für Schleier, 4. 6. 1942; PA/AA, Botschaft Paris 1125a. 
für Rassenfragen bieten sollte ${ }^{166}$. Ebenfalls federführend war sie bei der publikumswirksamsten Veranstaltung des Instituts, der Ausstellung „Le Juif et la France", die zwischen September 1941 und August 1942 mehr als 300000 Besucher in Paris, Bordeaux und Nancy anlockte. Sézille und seine Anhänger waren bei diesem Projekt schiere Statisten; sie sollten von einem stetig anschwellenden, überzeugten Judenhaß im Land künden, während hinter den Kulissen Botschaft und SD die Fäden zogen ${ }^{167}$.

Abetz hat später eingeräumt, daß die Ausstellung unterstützt wurde, weil Juden "die Hauptherde gegen die deutschen Interessen im Ausland bildeten" 168 . Er bereitete die Schau von langer Hand vor. Anfang März 1941 erkundigte er sich bei Generalkonsul Wüster in Rom, dem ehemaligen stellvertretenden Gaupropagandaleiter München-Oberbayern und Organisator der Ausstellung „Der ewige Jude", ob das Material für Paris verfügbar sei. Es könne kurzfristig wieder zusammengestellt werden, antwortete Wüster und empfahl als Ausstellungsgestalter seinen früheren Mitarbeiter Fritz v. Valtier, „welcher alle Einzelheiten kennt“. Der Unteroffizier wurde auf Abetz' Bitte im Juni nach Frankreich abkommandiert ${ }^{169}$. Auf 2000 Quadratmeter Fläche im Palais Berlitz, nahe der Oper, durfte er seine Ideen verwirklichen. Dem Publikum wurden drei Schwerpunkte präsentiert: Rassenkunde („unter besonderer Herausstellung von Léon Blum“), die „Verjudung“ Frankreichs sowie Gegenstrategien („Europa macht sich frei vom Juden“). Das Hauptthema - „Le péril juif“ - flimmerte selbst über eine Kino-Leinwand. Spezialisten der Informationsabteilung hatten den Film „Der ewige Jude“ für französische Verhältnisse überarbeitet und synchronisiert ${ }^{170}$.

In seiner Eröffnungsrede am 5. September 1941 betonte Capitaine Sézille, erst wenn das Judenproblem endgültig gelöst sei, könne ein „reines Frankreich“ an der Seite Deutschlands am kontinentalen Neuaufbau teilhaben. Daß Abetz diese Verknüpfung der Topoi Judenfrage ' und ,neue europäische Ordnung in seiner Berichterstattung herausstellte ${ }^{171}$, lenkt den Blick einmal mehr auf einen zentralen Ansatzpunkt der NS-Propaganda: Die besiegten Franzosen sollten stimuliert werden, den Besatzern durch ideologische Anpassung und aktive Unterstützung entgegenzukommen, um sich so einen vorteilhaften Platz im deutschen Herrschaftsgefüge zu verschaffen. $\mathrm{Da}$ das bilaterale Verhältnis auch in puncto Weltanschauung neuer Grundlagen bedürfe, hatte Friedrich Grimm schon im August 1940 Ministerpräsident Laval bedeutet: „Nach allem, was wir jetzt in Paris kennengelernt hätten, wären auch mir die Augen aufgegangen, daß die Regelung des Judenproblems für die Fortsetzung der deutsch-französischen Beziehungen und

166 Aufzeichnung Buscher, 14. 5. 1942, ebenda. Die Informationsabteilung trug „die volle Verantwortung für diese Schrift“.

167 Unzweideutig zur Rollenverteilung Abetz an Auswärtiges Amt, 5. 9. 1941; CDJC, V-72.

168 "Aktivität der Botschaft Paris in Judenfragen“; PA/AA, Nachl. Schleier/I.17.

169 PA/AA, Botschaft Paris 1788, Personalunterlagen v. Valtier.

170 Zusammenfassender Bericht Valtiers vom Juni 1943; PA/AA, Botschaft Paris 1191. Vgl. Kaspi, „Le Juif et la France“.

171 Abetz an Auswärtiges Amt, 8. 9. 1941; CDJC, VI-178. 
die kommende Neuordnung von geradezu entscheidender Bedeutung sei“"172. Nicht von ungefähr war es erklärtes Ziel der Ausstellungsmacher, Überzeugungsarbeit zu leisten und dem aus ihrer Sicht ungenügenden Rasseempfinden jenseits des Rheins auf die Sprünge zu helfen. Man habe der "politischen Schau einen beinahe dokumentarischen Charakter" geben wollen, resümierte Valtier unter Hinweis auf die im Lande vorherrschende Mentalität. „Denn ganz im Gegensatz zu Deutschland mußte hier der Franzose erst mit dem Problem an sich vertraut gemacht werden. Er ist mit sachlicher, ja fast pedantischer Beweisführung leichter zu überzeugen als mit Schlagtexten, und die Art und Form des Vortrags ist für ihn entscheidend. Die Ausführung der Ideen und Entwürfe wurde ausschließlich französischen Künstlern und Handwerkern übertragen. So blieb der beabsichtigte, gerade für diese Ausstellung notwendige französische Charakter bewahrt.“ Den praktischen Nutzen erkannte Valtier darin, daß ein „Klima für Aktionen“ geschaffen worden sei, „die Bevölkerung zum Teil noch schärfere Maßnahmen gegen die Juden forderte und die große Masse sich zumindest neutral verhielt “173.

\section{Motor der ,Endlösung in Frankreich: Judenreferent Carltheo Zeitschel}

Die Ausstellung „Le Juif et la France“ unterstreicht den Stellenwert antisemitischen Gedankenguts in der Botschaft. Besonders unrühmlich tat sich hierbei Judenreferent Carltheo Zeitschel hervor, im Verbund mit Dannecker ein Motor der ,Endlösung in Frankreich. Auf diesen Mann, dessen Spur sich in den letzten Kriegswirren verliert - er soll bei einem Bombardement Berlins umgekommen sein -, versuchten Abetz und Schleier später ein Gutteil Verantwortung abzuwälzen. Sie bezweifelten seine Zurechnungsfähigkeit, nannten ihn einen krankhaften Lügner, Wichtigtuer und Intriganten, der unbefugt eine wilde Korrespondenz geführt und ohne Wissen seiner Vorgesetzten Schriftstücke entworfen, unterzeichnet und abgeschickt habe. So bestritt Abetz die Urheberschaft eines Schreibens vom Mai 1942, das den Militärbefehlshaber zur Einführung des Judensterns auffordert. Schleier mochte sich partout nicht an zwei Telegramme vom März 1942 erinnern, die seinen Namen tragen und die Deportation von insgesamt 6000 Juden nach Auschwitz gutheißen („keine Bedenken“). Bei starker dienstlicher Beanspruchung seien von Mitarbeitern formulierte Stellungnahmen bisweilen erst nach Abgang vorgelegt worden, erklärte Schleier dazu; auch sei nicht auszuschließen,

172 Aufzeichnung Grimm über eine Besprechung mit Laval im Haus von Marcel Ribardière am 28. 8. 1940, pag. 8; PA/AA, Botschaft Paris 1270.

173 Bericht Valtier, Juni 1943. Am 20. 12. 1941 erhielt er das EK II und organisierte während seiner Pariser Zeit auch die Ausstellung „La vie nouvelle“. Im Februar 1943 wurde er zum Fronteinsatz abkommandiert. Abetz sprach von einem Verlust und bescheinigte seiner Arbeit einen „außergewöhnlich großen politischen und kulturpolitischen Erfolg“. Abetz an das stv. Generalkommando des 7. A.K. in München, 1.6. 1944; PA/AA, Botschaft Paris 1788. Kaspi, „Le Juif et la France“, und Marrus/Paxton, Vichy France, S. 212, bezweifeln die von deutscher Seite behauptete radikalisierende Breitenwirkung der Ausstellung „Le Juif et la France “; sie stützen sich auf die Korrespondenz Sézilles. 
daß Referenten Texte ganz einbehielten - aus Nachlässigkeit oder absichtlich. Während Abetz den Verdacht streute, "daß Zeitschel vom SD den Auftrag hatte, die Botschaft auf Touren zu bringen", behauptete Verteidiger Floriot, sein Mandant habe die Kreise des „Wahnsinnigen" einzuengen versucht, ihn jedoch wegen seiner langjährigen Parteizugehörigkeit nicht einfach abservieren können ${ }^{174}$.

Zeitschel, 1893 in Augsburg geboren, war eine schillernde Person. Nach dem Ersten Weltkrieg hatte er sein Medizinstudium beendet und als Schiffsarzt die Meere befahren. 1923 wurde er NSDAP-Mitglied, im April 1935 Mitarbeiter des Reichspropagandaministeriums (Abt. VII, Britisch-Indien und Ostasien). Ende 1937 wechselte er in die Politische Abteilung des Auswärtigen Amts, im Juni '39 trat er einen Konsulatsposten in Nigeria an. Nach dem Polenfeldzug zunächst nach Warschau beordert, folgte er 1940 als Angehöriger des Sonderkommandos v. Künsberg den vorrückenden deutschen Truppen im Westen. Mit einer Vollmacht Ribbentrops holte Abetz den Legationsrat und Major der Geheimen Feldpolizei im Juni an die Pariser Botschaft. 1943 kehrte Zeitschel nach Berlin zurück und schied auf eigenen Wunsch aus dem auswärtigen Dienst, weil er eine Italienerin heiraten wollte ${ }^{175}$. Er soll sich als unehelicher Sohn Kaiser Wilhelms II. ausgegeben haben ${ }^{176}$. Sein Amtsgebaren empörte auch Kollegen, die nach 1945 nicht auf der Anklagebank saßen, mithin weniger Grund hatten als Abetz, Schuld auf andere abzuladen. Presse-Fachmann Feihl titulierte Zeitschel als „Hochstapler“, der „überall herumschnüffelte“ und „durchaus in der Lage [war], sich vom Schreibtisch Briefköpfe zu nehmen und Stempel darunter zu machen, um seine Zwecke zu erreichen" 177 .

Trotz dieses üblen Leumunds war Zeitschel viel enger in das politische Tagesgeschäft eingebunden, als Abetz und Schleier im nachhinein behaupteten. Ihre Darstellung, er habe weder zum festen Personalstamm der Botschaft gehört noch offiziellen Umgang mit anderen Dienststellen gepflogen ${ }^{178}$, darf im Spiegel der Akten als widerlegt gelten. In Geschäftsverteilungsplänen ist Zeitschel beim Referat Protokoll angesiedelt, „zur besonderen Verwendung “ und für „Sonderaufgaben " 179 . Er war Verbindungsmann zum Deutschen Roten Kreuz und verantwortlich für die Gebäude des französischen Außenministeriums, in denen nun die Archivkommission des Auswärtigen Amts arbeitete. In der zweiten Jahreshälfte 1940 kümmerte er sich um die in Paris verbliebenen Diplomaten anderer Staaten und die „Sicherstellung“ jüdischen Kunstvermögens. Anfang 1941 wurde er Sach-

174 Abetz-Prozeß, 15.7. 1949, pag. 92ff; AN, 334 AP 49. Vernehmung am 6.7. 1948, pag. 3 ff.; IMT, KV-Anklage, Interrogations, A 2. „Aktivität der Botschaft Paris in Judenfragen“; PA/AA, Nachl. Schleier/I.17. Schriftliche Stellungnahme Schleiers zu einem französischen Auslieferungsbegehren von 1949, ebenda, I.10. Schleier, „Deutsche Polizei in Frankreich“, ebenda, I.4. Zum fraglichen Abetz-Telegramm siehe Prozeß-Protokoll und PA/AA, R 100869; zu Schleiers Telegrammen IMT, NG-4954.

175 PA/AA, Personalakte Dr. Carltheo Zeitschel. Zeitschel an Auswärtiges Amt, 24. 6. 1940; PA/AA, R 29587.

176 Abetz, Vernehmung am 6. 7. 1948 und öfter.

177 Vernehmung Feihls durch Robert Kempner am 15. 12. 1947; IMT, KV-Anklage, Interrogations, F 12.

178 Abetz, „Aktivität der Botschaft“; Schleier, „Deutsche Polizei in Frankreich“.

179 IMT, NG-5470; PA/AA, Nachl. Schleier/III.19. 
bearbeiter für Judenfragen - damals schlugen die Besatzer eine verschärfte Gangart in der Judenpolitik ein ${ }^{180}$. Kernstück seines neuen Auftrags war die Abstimmung mit Sipo und SD; ihre Bedeutung unterstreicht Abetz' Vorstoß, Zeitschel zum Obersturmbannführer zu befördern, als 1942 ein Höherer SS- und Polizeiführer mit eigener Exekutivgewalt in Paris Einzug hielt. Damit werde der Aufgabenbereich des Sicherheitsdienstes erweitert, kombinierte Abetz; folglich sei die Botschaft daran interessiert, „daß ihr Verbindungsmann zur SS und zum SD in Frankreich rangmäßig entsprechend aufgewertet wird"181. Im November 1941 wurde Zeitschel überdies die ständige Verbindung zum Generaldelegierten der französischen Regierung für die besetzten Gebiete, de Brinon, übertragen ${ }^{182}$. Kaum auszudenken, daß der Botschafter den direkten Draht zu einem so engen Weggefährten und überzeugten Kollaborateur jemandem überließ, der nicht sein Vertrauen genoß. Die Wahl eines notorischen Antisemiten mochte Teil seiner Bemühungen sein, französische Behörden zu selbständigen Schritten bei der ,Endlösung' zu drängen.

In der Botschaft gebärdete sich Zeitschel als Scharfmacher und Sachwalter des $\mathrm{SD}$. Beharrlich trieb er die Diplomaten an, für die Internierung möglichst vieler Juden zu sorgen, suchte die Deportationen zu beschleunigen und schreckte in seinen radikalen Forderungen vor nichts zurück. Am 21. August 1941 legte er Abetz nahe, Hitler die Sterilisation sämtlicher Juden im deutschen Herrschaftsbereich zu empfehlen ${ }^{183}$. Tags darauf warb er für den Plan eines Juden-Reservats in den eroberten Ostgebieten, in seinen Augen eine überlegene Alternative zum Madagaskar-Plan: "Wir könnten dann Europa in kürzester Zeit judenfrei haben." Abetz möge sich in Berlin für eine solche Lösung verwenden und hervorheben, daß in Frankreich "nicht genügend Lager zur Verfügung stehen und man sich infolgedessen mit allen möglichen Gesetzen und Vorschriften durchhelfen muß, die doch im Grunde gesehen nur vorübergehende und nicht durchgreifende Maßnahmen sind“184. Die Beispiele ließen sich mühelos fortsetzen. Regelmäßige Schriftvermerke des Juden-Referenten erhärten die Annahme, daß der Botschafter über seine Umtriebe im Bild war und ihn als Impulsgeber, Informanten und Mittelsmann akzeptierte. Er räumte später ein, Zeitschels Aufzeichnungen teilweise als Grundlage für eigene Berichte benutzt zu haben ${ }^{185}$. Vor Gericht sagte Abetz, sei-

180 Jahresbilanz Zeitschel, 13. 6. 1941; PA/AA, Botschaft Paris 1321. Aufzeichnung der Botschaft vom 27. 5. 1942, „Betrifft: Personalbestand“; CDJC, DLXVI-2, abgedruckt Klarsfeld (Hrsg.), Endlösung, S. 18. Dort die Bestätigung: „Zeitschel bearbeitet innerhalb der Politischen Abteilung die Juden- und Freimaurerfragen".

181 Abetz an Likus (AA), 25. 3. 1942; PA/AA, R 27174.

182 Abetz an Brinon, 19. 11. 1941: „Von dieser Maßnahme erhoffe ich eine Erleichterung des gegenseitigen Verkehrs." CDJC, LXXI-68.

183 Zeitschel, Aufzeichnung für Abetz, 21. 8. 1941, abgedruckt Klarsfeld, Vichy-Auschwitz, S. 367.

184 Zeitschel für Abetz, 22. August, ebenda, S. 367f. Bevor Abetz Mitte September ins Führerhauptquartier aufbrach, drängte Zeitschel ihn erneut, das Abschiebeproblem zur Sprache zu bringen, „damit wir die einzigsten kümmerlichen Lager, die wir zur Verfügung haben, freibekommen, um weitere Juden internieren zu können“" Notiz vom 10. 9. 1941; CDJC, LXXI-65.

185 Abetz, „Eidliche Erklärung" vom 30. 5. 1947, pag. 11; CDJC, LXXI-123. 
nem Rechtfertigungsmuster des strategischen Doppelspiels folgend, er habe Zeitschel in der Rolle des linientreuen Parteiveteranen gelitten, hinter dessen Rücken sich eine gemäßigte Politik auf anderen Feldern entfalten konnte. Bei dieser Gelegenheit zeigte er einen seltenen Anflug von Reue: "Je porte volontiers la faute du mal qui est arrivé du fait de cette nomination." 186

Damit einhergehende Versuche, den früheren Mitarbeiter zu desavouieren, verfingen jedoch ebensowenig wie Beteuerungen, nichts vom grausamen Schicksal gewußt zu haben, das die deportierten Juden erwartete. Als der Holocaust der Weltöffentlichkeit längst bekannt war, verschanzte sich Abetz immer noch hinter der verlogenen Formel vom "Arbeitseinsatz im Osten ${ }^{\text {“187. }}$. Schleier behauptete: „Von der vorsätzlichen und planmäßigen Tötung [...] ist weder mir noch irgend einem Beamten der Botschaft auch nur das Geringste bekannt gewesen. Es war uns vom SD mitgeteilt worden, daß sich neben dem KZ Auschwitz in Oberschlesien Industriewerke der Rüstungsindustrie befänden, in denen die Juden beschäftigt wurden." Dem Botschaftspersonal sei bei dieser Auskunft „ein Stein vom Herzen" gefallen; man habe annehmen dürfen, durch ein "Ja" zu Deportationen Geiselerschießungen zu verhindern und Leben zu retten ${ }^{188}$. Dem steht entschieden das Bekenntnis Walter Bargatzkys gegenüber. Schon vor dem Sommer 1942, bestätigte der Kriegsverwaltungsrat im besetzten Paris, „haben wir Nachrichten erhalten, daß man die Juden im Osten planmäßig und massenweise tötet ". Aus Rußland abkommandierte Wehrmachtangehörige verbreiteten Details über das Wüten der Einsatzgruppen, Berichte von Massakern kursierten auch unter AABeamten ${ }^{189}$. Von da an, so Bargatzky, habe es auch im Westen „kein Nichtwissen mehr" gegeben ${ }^{190}$. Es scheint ausgeschlossen, daß das Wissen um die Verbrechen nicht bis in die Rue de Lille vordrang, als Razzien und Transporte im großen Stil einsetzten. Abetz' Entourage war zumindest oberflächlich informiert und bestrebt, Klarheit zu gewinnen, wie eine Anfrage Zeitschels beim Auswärtigen Amt belegt. Auf „vertraulichem Wege“ begehrte er Aufschluß über jene Staatssekretärbesprechung im Januar 1942, die als Wannsee-Konferenz bekannt wurde und eine neue Stufe in der Planung und Organisation des Völkermords markierte191.

„Die Ausrottung der Juden“, resümiert Raul Hilberg, „[wurde] ein offenes Geheimnis." ${ }^{192}$ Aus Frankreich fielen ihr schätzungsweise 76000 Menschen zum

186 Abetz-Prozeß, 15. 7. 1949, pag. 151 f.; AN, 334 AP 49.

187 Ebenda, pag. 115.

188 Schriftliche Stellungnahme Schleiers zu einem französischen Auslieferungsantrag von 1949, pag. 8 f.; Protokoll eines Kreuzverhörs vor dem Extraditionstribunal Hamburg, Mai/Juni 1949; PA/AA, Nachl. Schleier/I.

189 Browning, Final Solution, S. $72 \mathrm{ff}$.

190 Bargatzky, Hotel Majestic, S. 101 ff. Ernst Jünger, dem Stabe des Militärbefehlshabers zugeteilt, erwähnt die Massenvernichtung im Osten mit Datum vom 16. 10. 1943 in seinem Pariser Tagebuch: „Dort also verschwinden die Massen von Juden, die man aus Europa zur ,Umsiedlung“ verschickt." Strahlungen, S. $433 \mathrm{f}$.

191 Zeitschel an Dr. Strack, 23. 3. 1942: „Der Inhalt der Besprechung ist, wie Sie verstehen werden, für meine Aufgabe, Behandlung der Judenfrage, von grundlegender Bedeutung. “ IMT, NG-5412. Ausführlich zur Wannsee-Konferenz Pätzold/Schwarz, Tagesordnung: Judenmord; Aly/Heim, Vordenker, S. $453 \mathrm{ff}$.

192 Hilberg, Vernichtung, 3, S. 1081. 
Opfer, darunter zwei Drittel staatenlose Juden und mehr als 10000 Kinder und Jugendliche. Die meisten starben in Auschwitz, annähernd 3000 bereits vor der Deportation in den Internierungslagern, etwa 1100 wurden ohne Gerichtsverfahren erschossen oder erschlagen. Nur etwa 2600 Personen haben die Deportation überlebt ${ }^{193}$. Die Geschichte der Deutschen Botschaft Paris wie auch Abetz' Biographie sind unauslöschlich mit dieser Schreckensbilanz verknüpft.

193 Diese Angaben nach Juliane Wetzel, Frankreich und Belgien, in: Benz (Hrsg.), Dimension des Völkermords, S. 127 f., im wesentlichen gestützt auf die minutiösen Recherchen von Serge Klarsfeld. 